\title{
A historical review of surgery for peritonitis secondary to acute colonic diverticulitis: from Lockhart-Mummery to evidence- based medicine
}

\author{
Roberto Cirocchi ${ }^{1}$, Sorena Afshar ${ }^{2}$, Salomone Di Saverio ${ }^{3^{*}}$ (D), Georgi Popivanov ${ }^{4}$, Angelo De Sol ${ }^{5}$, \\ Francesca Gubbiotti ${ }^{6}$, Gregorio Tugnoli ${ }^{3}$, Massimo Sartelli ${ }^{7}$, Fausto Catena ${ }^{8}$, David Cavaliere ${ }^{9}$, Renata Taboła ${ }^{10}$, \\ Abe Fingerhut ${ }^{11,12}$ and Gian Andrea Binda ${ }^{13}$
}

\begin{abstract}
The management of patients with colonic diverticular perforation is still evolving. Initial lavage with or without simple suture and drainage was suggested in the late 19th century, replaced progressively by the three-stage Mayo Clinic or the two-stage Mickulicz procedures. Fears of inadequate source control prompted the implementation of the resection of the affected segment of colon with formation of a colostomy (Hartman procedure) in the 1970's. Ensuing development of the treatment strategies was driven by the recognition of the high morbidity and mortality and low reversal rates associated with the Hartman procedure. This led to the wider use of resection and primary anastomosis during the 1990's.

The technique of lavage and drainage regained popularity during the 1990's. This procedure can also be performed laparoscopically with the advantage of faster recovery and shorter hospital stay. This strategy allows resectional surgery to be postponed or avoided altogether in many patients; and higher rates of primary resection and anastomosis can be achieved avoiding the need for a stoma. The three recent randomized controlled trials comparing laparoscopic peritoneal lavage alone to resectional surgery reported inconsistent outcomes.

The aim of this review is to review the historical evolution and future reflections of surgical treatment modalities for diffuse purulent and feculent peritonitis. In this review we classified the various surgical strategies according to Krukowski et al. and Vermeulen et al. and reviewed the literature related to surgical treatment separately for each period.
\end{abstract}

Keywords: Acute diverticulitis, Emergency surgery, Perforated diverticulitis, Laparoscopic lavage, Colorectal surgery, Acute care surgery, Hartmann resection

\section{Background}

Colonic diverticulosis is an increasingly common clinical condition in Western Europe and North America [1]. Most people with colonic diverticula will remain completely asymptomatic. However, $10-20 \%$ of patients with diverticulosis will manifest symptoms and signs of illness. Symptomatic diverticular disease (DD) can be separated into DD without inflammation (75\%) and with

\footnotetext{
* Correspondence: salo75@inwind.it; salomone.disaverio@gmail.com ${ }^{3}$ General (Colorectal) Emergency and Trauma Surgery Service, Maggiore Hospital Regional Emergency Surgery and Trauma Center - Bologna Local Health District, Bologna, Italy

Full list of author information is available at the end of the article
}

inflammation or diverticulitis [2]. The former can also be painful in spite of the lack of inflammation [2]. Acute diverticulitis is defined as acute inflammation of a colonic diverticulum [3]. Peridiverticular and pericolic infections are a result of microscopic or macroscopic perforation of a diverticulum. The spectrum of acute diverticulitis varies between mild diverticulitis and diffuse feculent peritonitis [4]. Starting in 1978, Hinchey's classification has been used for the staging of complicated diverticulitis [5]. Several modifications of Hinchey's traditional classification have been proposed [6, 7] (Table 1).

The European Association for Endoscopic Surgeons (EAES) classification system divides the severity of 
Table 1 Hinchey classification of perforated diverticulitis

\begin{tabular}{ll}
\hline Hinchey stage & Features of disease \\
\hline Stage $I^{a}$ & Diverticulitis with a pericolic abscess \\
Stage $\|^{b}$ & $\begin{array}{l}\text { Diverticulitis with a distant abscess } \\
\text { (this may be retroperitoneal or pelvic) }\end{array}$ \\
Stage III & Purulent peritonitis \\
Stage IV & Fecal peritonitis \\
\hline
\end{tabular}

${ }^{\mathrm{a}}$ Stage I has been divided into la (phlegmon) and lb (confined pericolic abscess) ${ }^{\mathrm{b}}$ Stage II has been divided into distant abscesses amendable for percutaneous drainage (stage Ila) and complex abscesses associated with a possible fistula (stage Ilb)

diverticulitis into three different grades of disease [8] (Table 2). In-hospital mortality after emergency surgery for acute perforated diverticulitis is high (29\%) and the Hinchey stage has been found to be a significant predictive factor for mortality [9].

The main cause for the high mortality rate is due to sepsis and prognosis is associated with severity of peritonitis as measured by scoring systems such as the Acute Physiology and Chronic Health Evaluation (APACHE), Mannheim peritonitis index (MPI) and Sequential Organ Failure Assessment (SOFA) [10, 11]. SOFA score was developed to assess organ dysfunction and morbidity and in contrast to APACHE II it allows serial follow-up [11]. The predictive value for death at admission and after $72 \mathrm{~h}$ is $75 \%$ and $84 \%$ respectively [12].

According to current practice guidelines, patients with generalized peritonitis should undergo emergency surgery, as suggested by Mikulicz in 1889 [13]. However, despite intensive research carried out during the last century, the best treatment algorithm is yet to be determined.

The aim of this review is to expose the historical evolution and future reflections of surgical treatment modalities for purulent and feculent peritonitis.

\section{Methods}

Surgical strategies were stratified according to the classifications proposed by Krukowski et al. and Vermeulen et al. [14, 15] (Table 3). We reported the essential

Table 2 European Association for Endoscopic Surgeons classification system for colonic diverticulitis (1999)

\begin{tabular}{lll}
\hline Grade of disease & Description & Clinical state of the patient \\
\hline II & $\begin{array}{l}\text { Symptomatic } \\
\text { uncomplicated } \\
\text { disease }\end{array}$ & $\begin{array}{l}\text { Pyrexia, abdominal pain, CT } \\
\text { findings consistent with } \\
\text { diverticulitis }\end{array}$ \\
III & $\begin{array}{l}\text { Recurrent } \\
\text { symptomatic } \\
\text { disease }\end{array}$ & \\
Complicated & $\begin{array}{l}\text { Bleeding, abscess formation, } \\
\text { phlegmon, colonic perforation, } \\
\text { disease }\end{array}$ & strulent and fecal peritonitis, \\
& & \\
\hline
\end{tabular}

Table 3 Operative Procedures

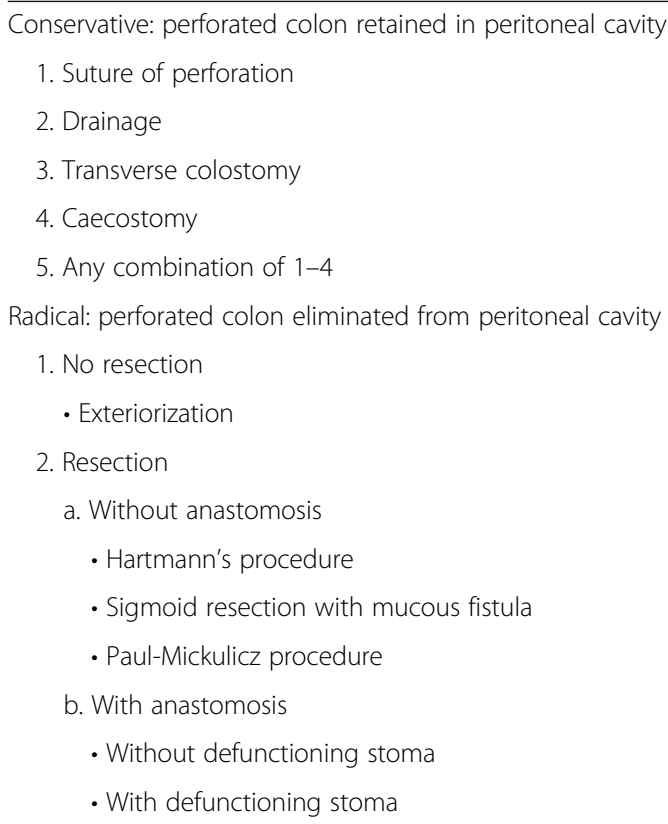

literature relating to surgical treatment separately for each decade from 1900 to 2016 . Only the highest grade of evidence published for each topic was noted for each period. The hierarchy of evidence grading system proposed by the Centre for Evidence-Based Medicine of Oxford was used [16].

This systematic review was performed in accordance with the Preferred Reporting Items for Systematic Reviews and Meta-analyses (PRISMA) standards (Fig. 1) [17]. We conducted a systematic literature search using PubMed employing the terms perforated OR peritonitis AND diverticulitis; we search in the published papers from January 1st 1990 to May 2016 [18]. The PubMed function "related articles" was used to broaden each search, and the reference list of all potentially eligible studies was analysed. In addition, a manual search method including the Science Citation Index Expanded, Scopus and Google Scholar databases was performed. After this initial screening process, two authors (RT, RC) independently assessed eligibility of full-text papers. The final decision on eligibility was reached by consensus between the two authors. When multiple articles were published from a single study group and where overlapping study periods were reported, only the most recent article was considered to avoid duplication of data. Data were extracted based on an intention-to-treat principle. Any disagreement was resolved through discussion with a reassessment of the data and/or by involving a senior author.

\section{Results}

The PRISMA flow diagram for systematic reviews is presented in Fig. 1. We identified 2,403 publications using 


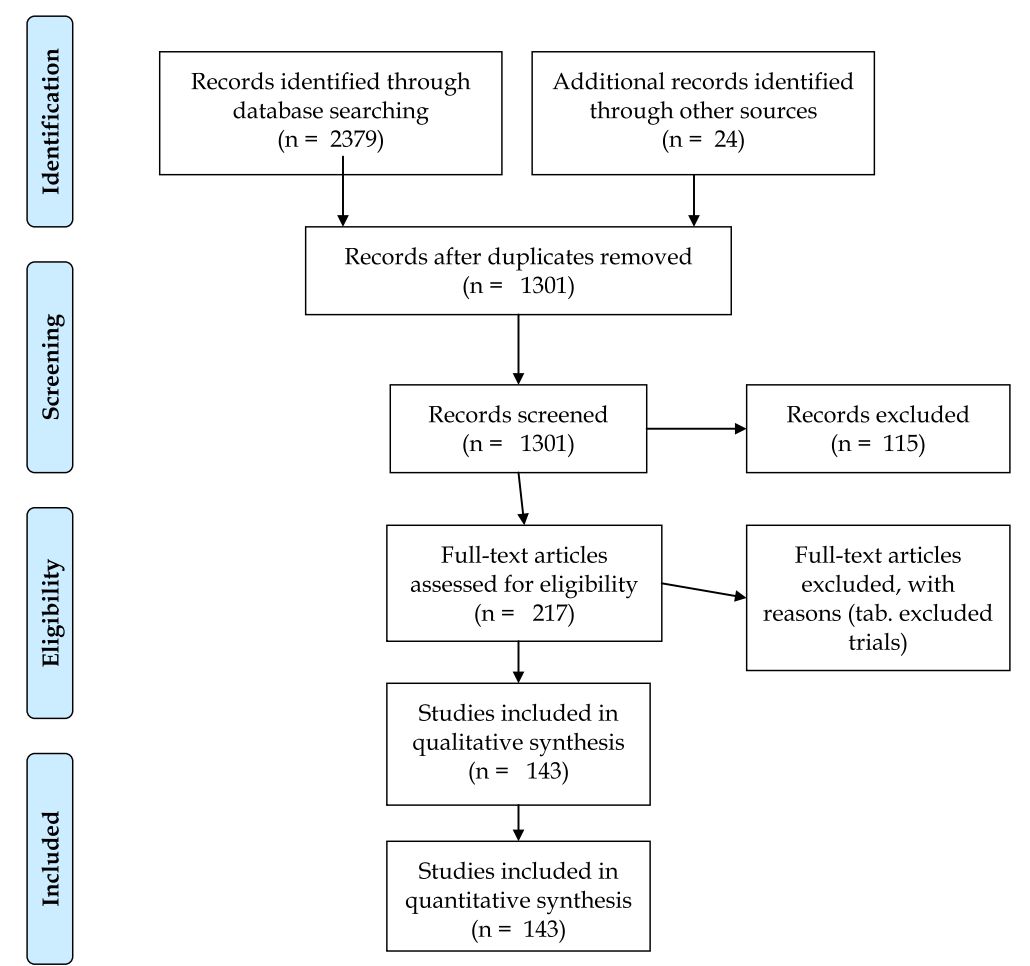

Fig. 1 Prisma flow diagram of the study

the literature search strategy described above and additional searches through other sources. After excluding 2,186 records following the duplicate removed and the review of the titles and abstracts, 217 abstracts eligible for full-text evaluation remained. After full-text assessment we identified 143 publications that fulfilled the inclusion criteria.

Surgical treatment of acute generalized peritonitis from diverticulitis was described as early as 1910 by Lockhart-Mummery [19] who advocated washing the peritoneum and abdominal drainage, combined, if possible, with suture of the colonic perforation (Tables 4 and 5) [19-113].

In the same decade Mikulicz described his two-stage technique of intestinal resection and anastomosis in a well-known article entitled "Surgical Experiences with Intestinal Carcinoma" presented for the first time to the Thirty-First Congress of the German Society of Surgery in 1903 [114]. Along with the description of details of his technique for intestinal resection, he also reported his personal experience in 106 patients, 16 of whom underwent a two-stage technique because he considered performing the initial anastomosis to be too hazardous for the treatment of intestinal cancer and so advocating to limiting the procedure in some cases to the resection and a double-barreled colostomy. Mikulicz strongly recommended this two-stage technique for all resections and anastomoses of the large and small bowel when the bowel was obstructed. This technique was then subsequently adopted for the treatment of diverticulitis.

In 1924 an observational study from the Mayo Clinic advocated drainage and suture of the colonic perforation as well as selective use of a diverting colostomy [115]. However, in some cases, fecal fistulas developed and some became chronic. In cases of substantial infection in or close to the colon, or in the presence of a colovesical fistula or fistula with other structures, the mortality decreased substantially with use of a diverting colostomy. However, in some cases the local suture of the perforation had been unsatisfactory because of difficulties visualizing the perforation, as well as difficulty in suturing edematous bowel wall. During the same decade Henri Hartmann proposed his surgical technique consisting of sigmoid resection, burying the rectal stump and performing terminal colostomy for the treatment of rectal cancer, as an alternative to abdomino-perineal resection, commonly called Hartmann's procedure (HP) [116]. Hartmann had not originally advocated subsequent restoration of intestinal continuity.

In 1930 Rankin and Brown standardized the threestage procedure developed by Mayo in 1907 [21, 115]. The first stage of the procedure consisted of peritoneal lavage, drainage of any abscess and creation of a proximal colostomy. The second stage was performed after a period of 2 to 4 months and involved resection of the sigmoid colon with end-to-end anastomosis. The third 


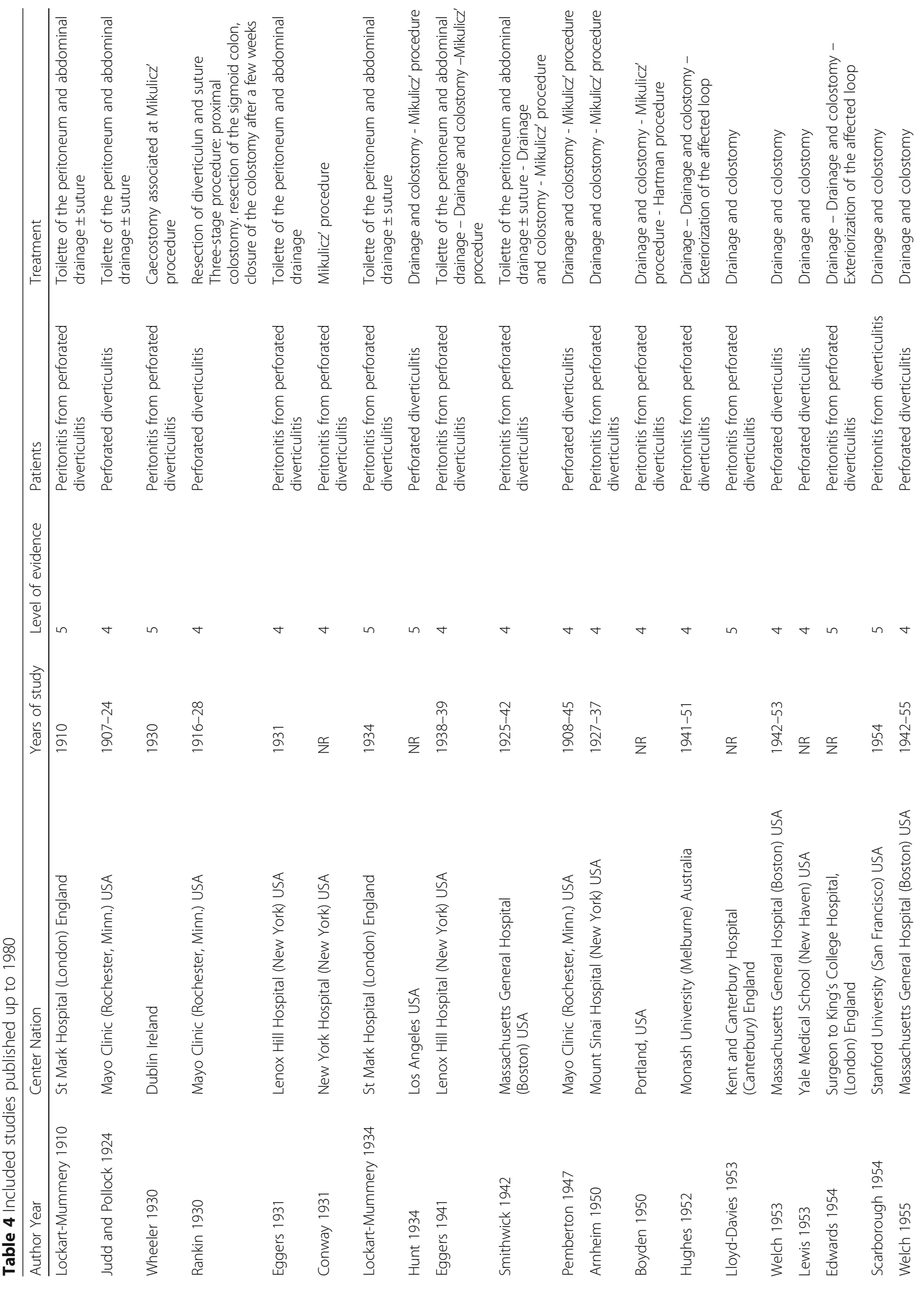




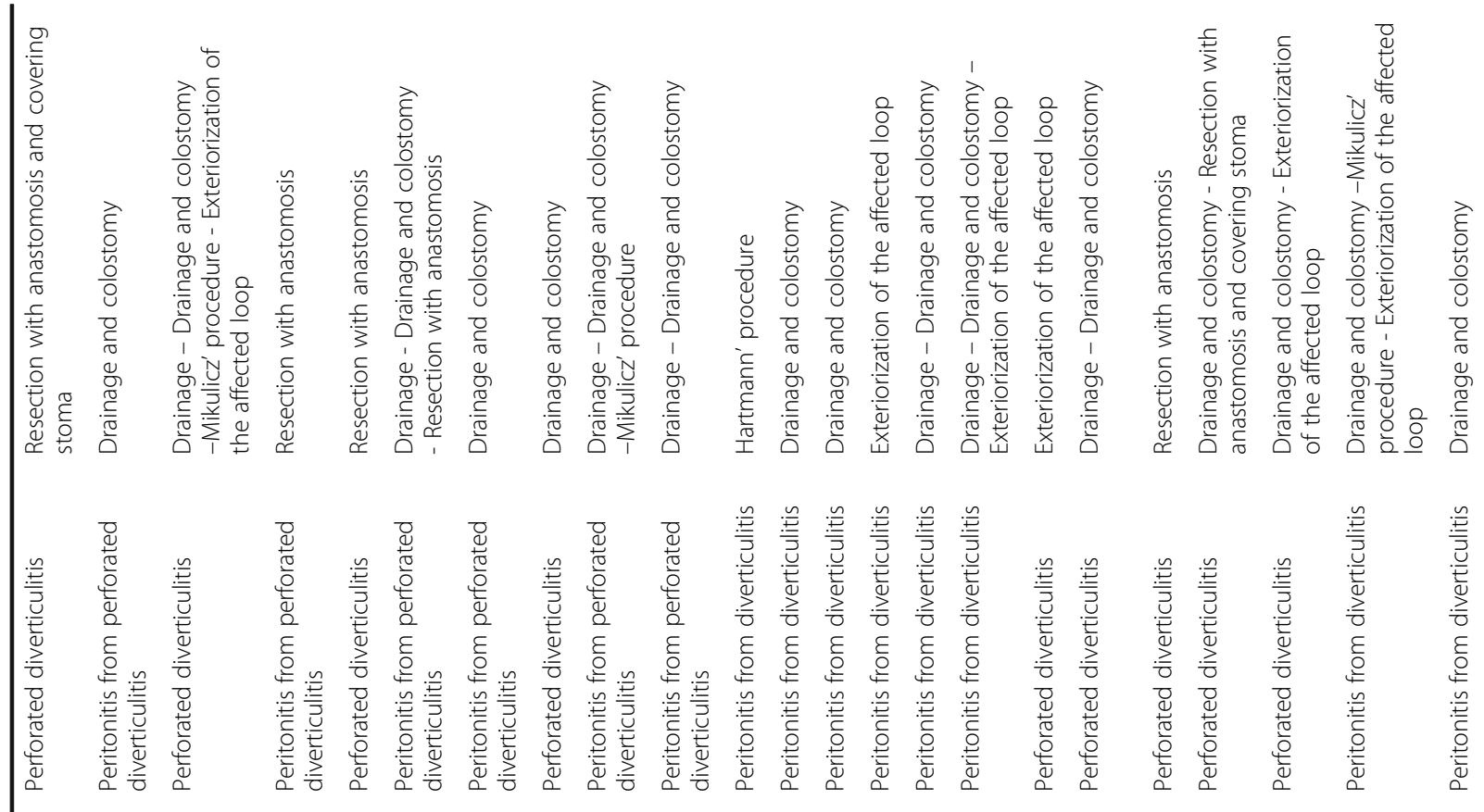

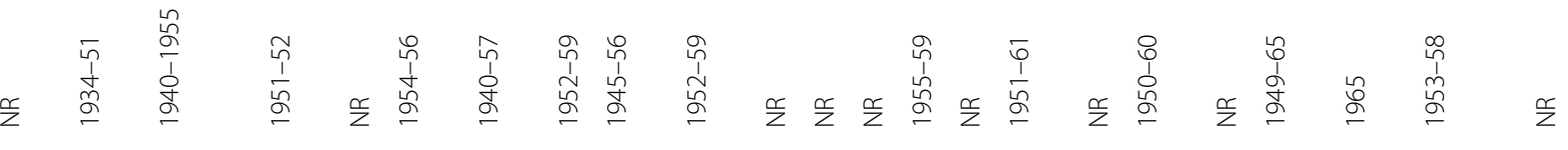

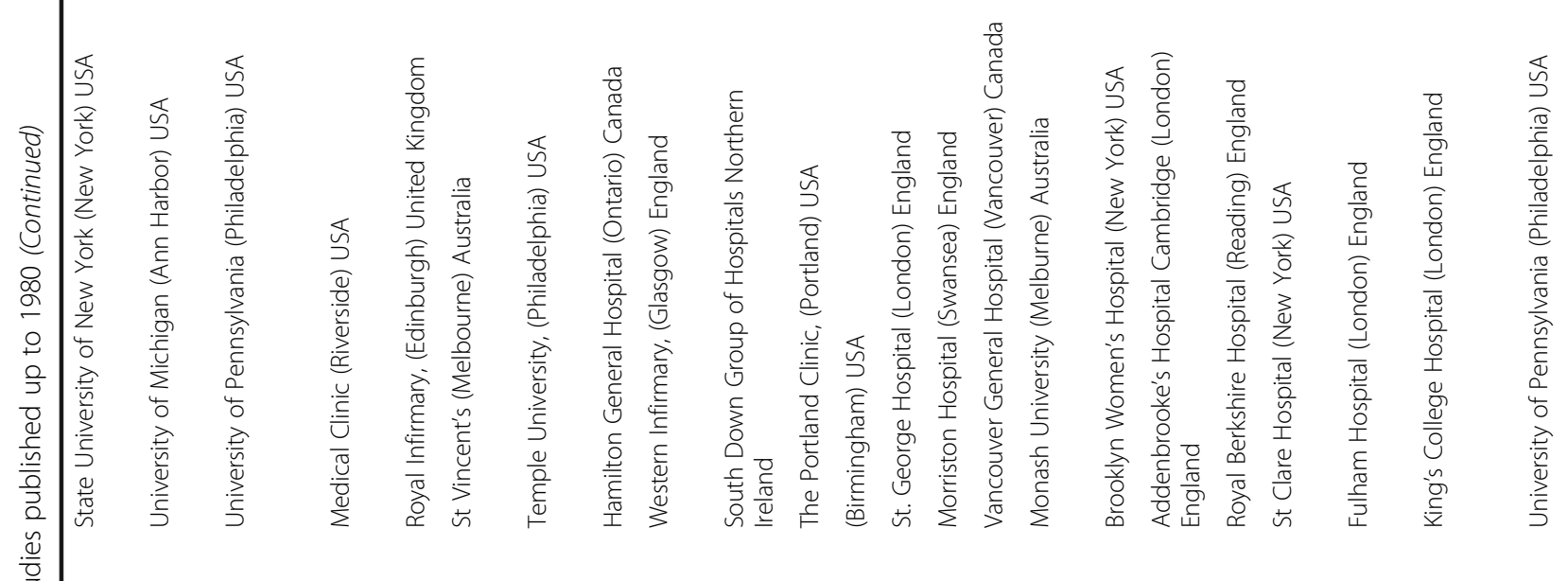

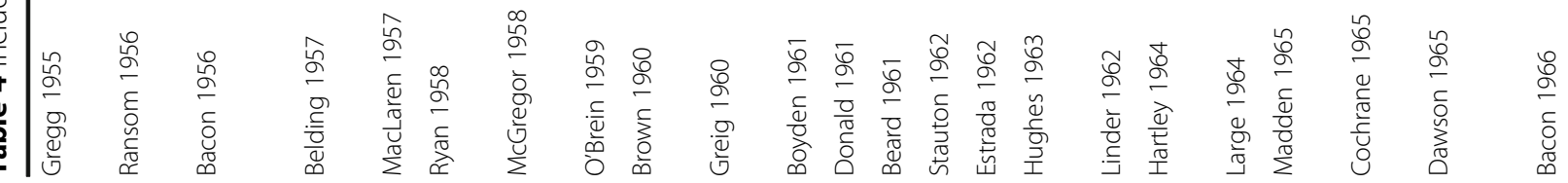




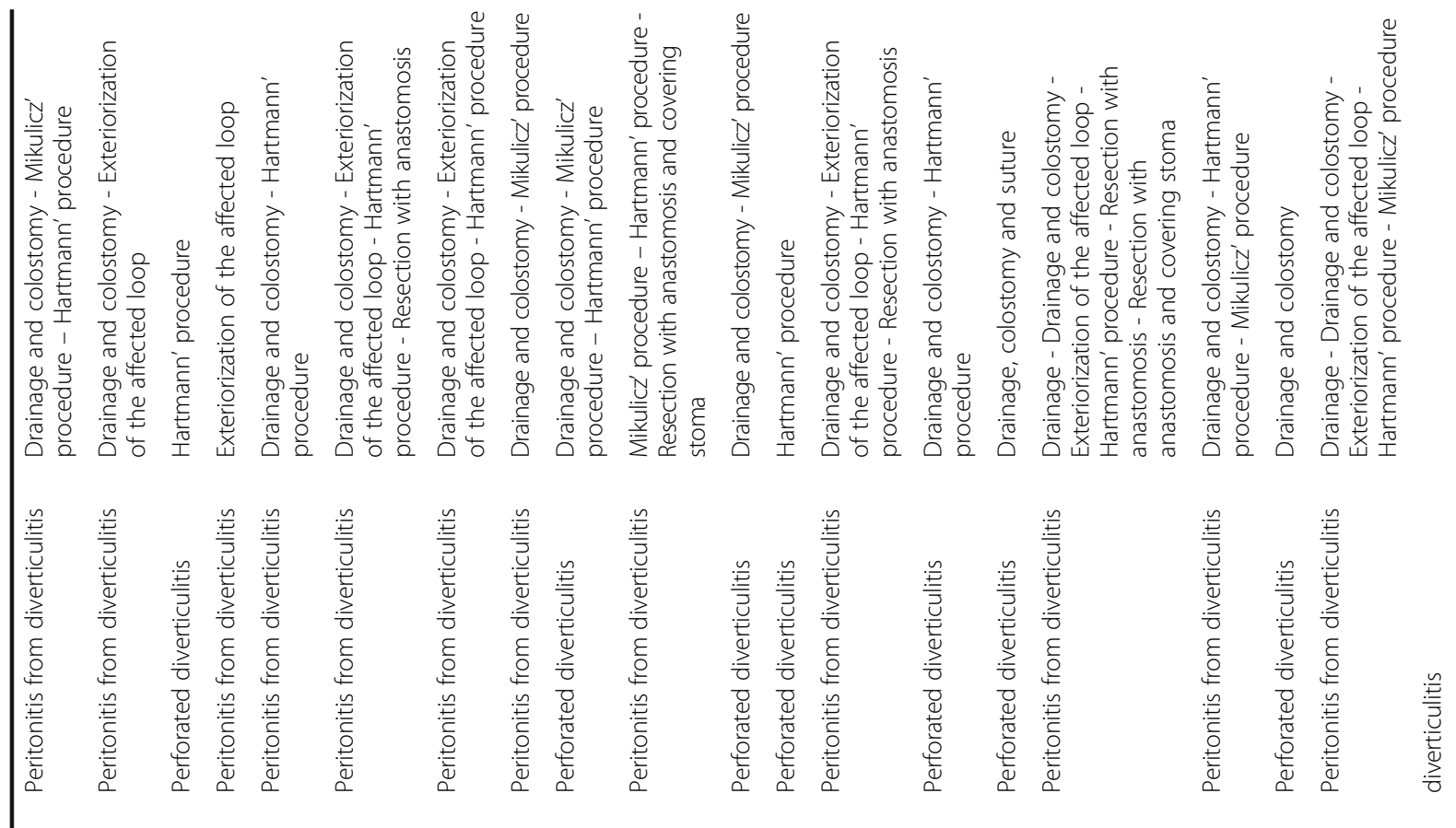

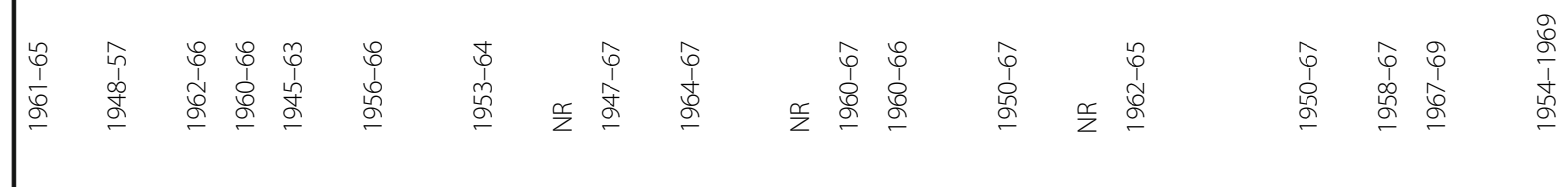

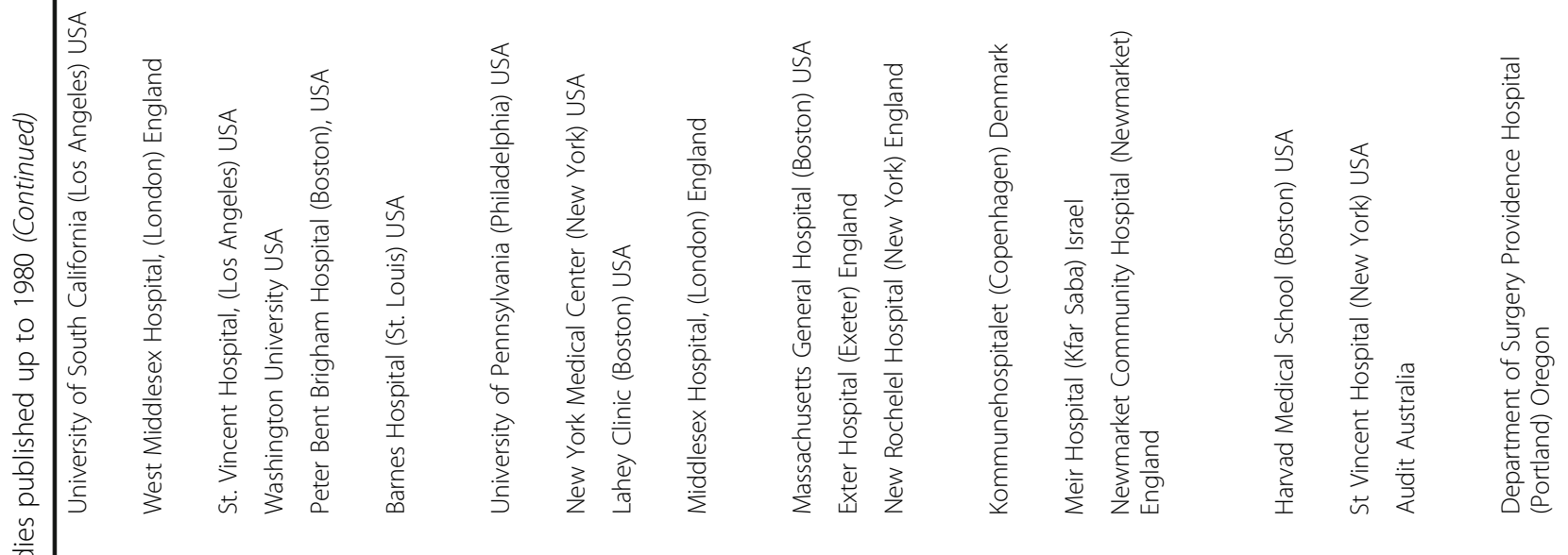




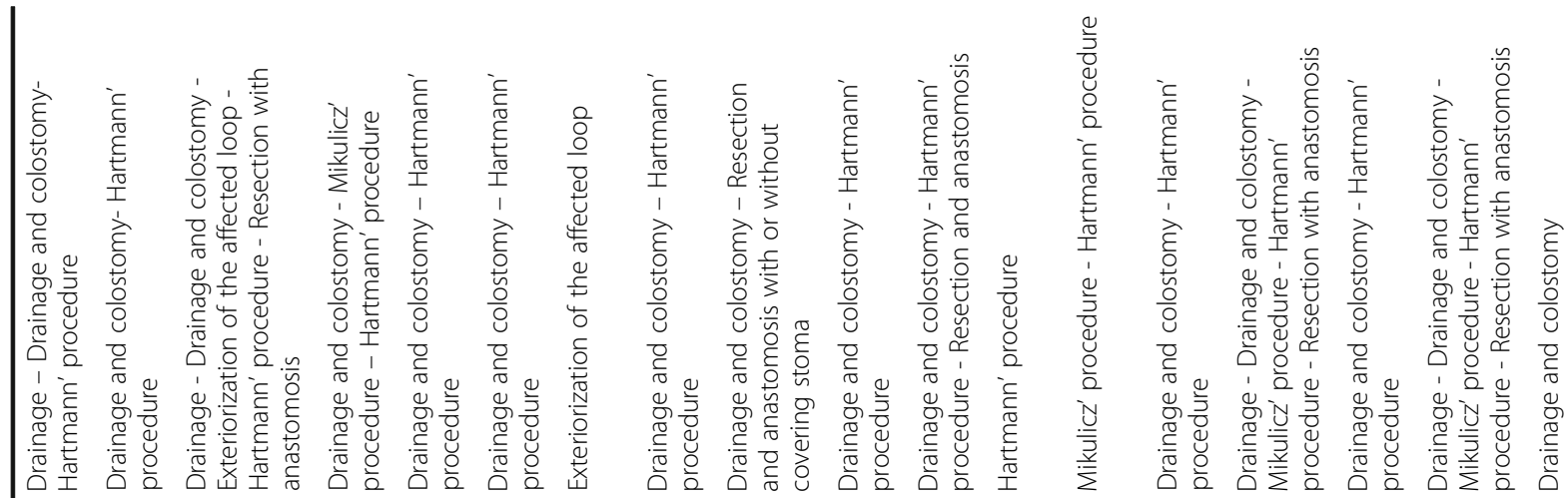

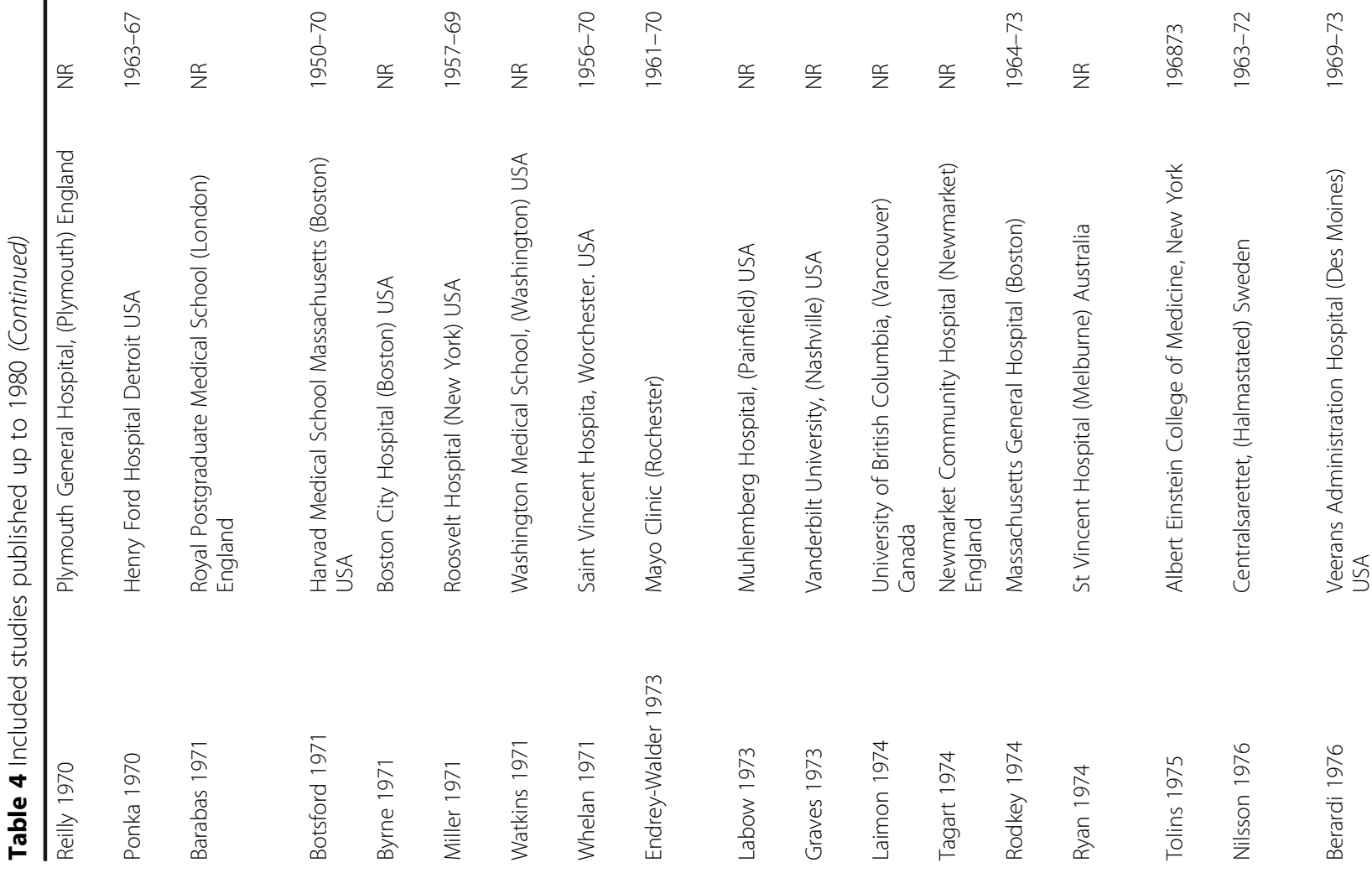




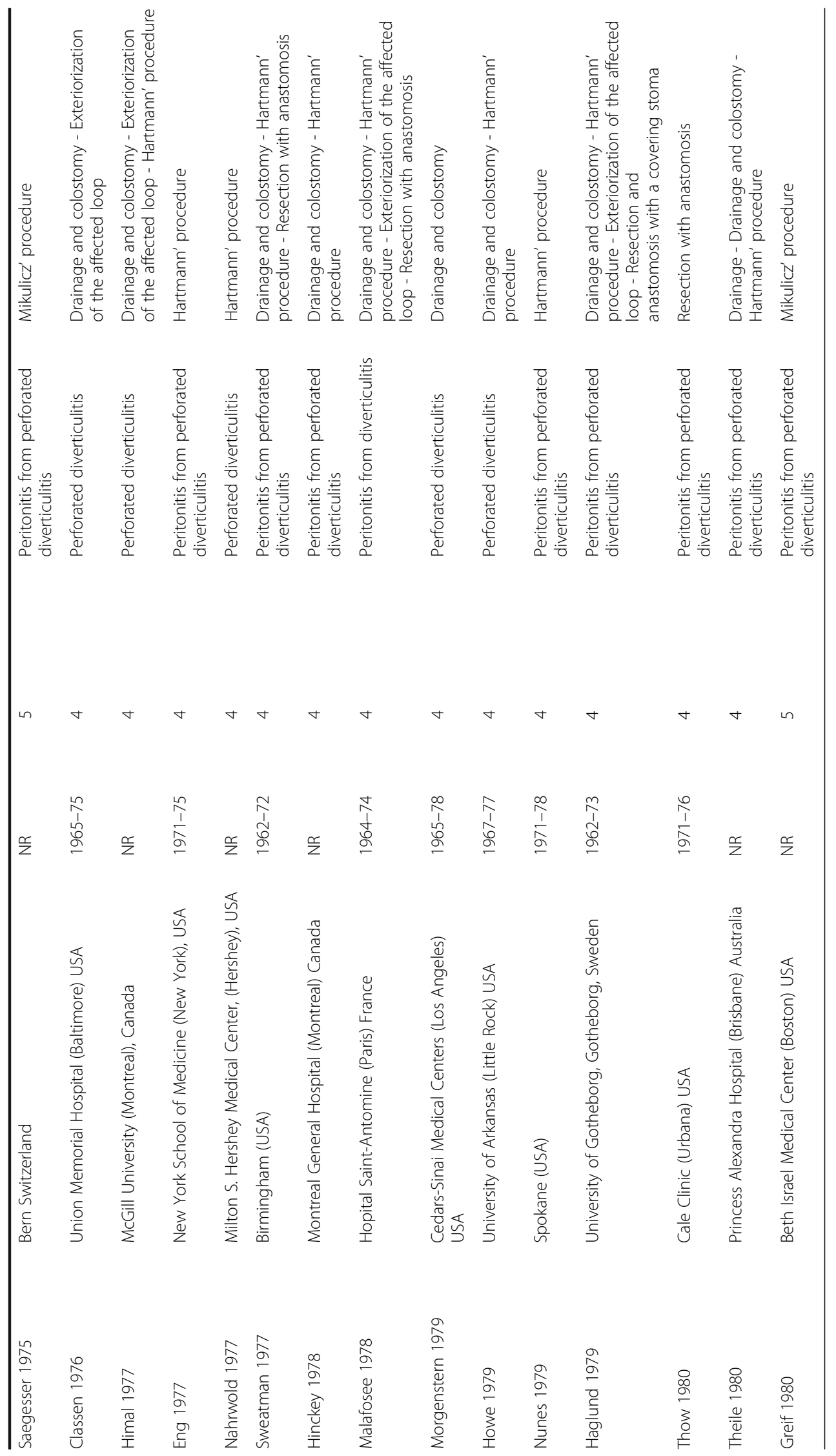




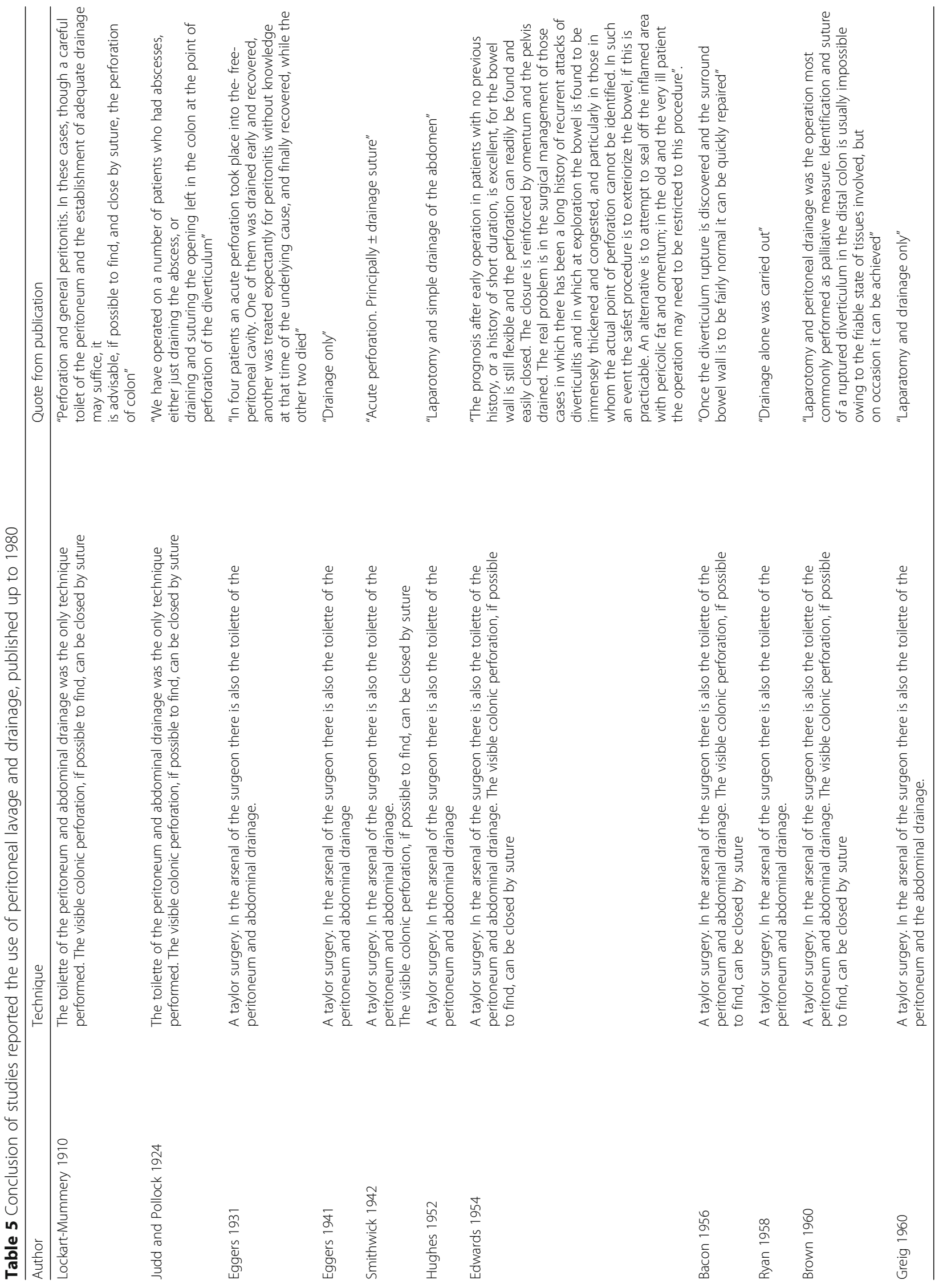


stage consisted of closure of the colostomy a few weeks after the second stage to ensure healing of the anastomosis.

In 1934 Lockhart-Mummery changed his original surgical technique, based only on peritoneal toilette and abdominal drainage by adding the use of a proximal diverting colostomy [23]. The right half of the transverse colon was used to create the colostomy. This approach was subsequently shown to leave the left colon and splenic flexure free from adhesions and favor the ensuing sigmoidectomy [117]. However, drainage and colostomy were associated with a higher mortality and morbidity because further leakage occurred from the site of perforation in spite of the proximal colostomy in some cases. Moreover, the inflamed colon could represent a source of sepsis and leaving this in situ was not seen as an attractive option. For these reasons, many surgeons, including Arhneim and Egger, favored the Mikulicz procedure [24, 118]. However, while most surgeons approved the theoretical advantages of Mikulicz' exteriorization, they believed that this technique could be performed in very limited cases, because of the surrounding adhesions and edematous bowel [25, 119].

The three-stage procedure was the standard treatment of acute diverticulitis until the late 1940's. "Palliative" treatment, consisting of formation of a colostomy alone, without subsequent resection, was almost partially abandoned during this period. Interval closure of the colostomy without colon resection led to a high proportion of aggravation of symptoms- over 45 and $70 \%$ of patients, in Smithwick's and Pembertonet al.'s experiences, respectively [27, 28]. During this period, the use of the $\mathrm{HP}$ for the treatment of recto-sigmoid cancer decreased in favor of resection and primary anastomosis (PRA). At the same time, HP gained in popularity as a treatment of complications of DD and other emergency conditions while antibiotics were introduced into clinical practice. In 1950 Boyden articulated this approach and proposed a technical variation: a long distal bowel stump was exteriorized through the hypogastrium [29].

During this period, drainage of pus and formation of a proximal colostomy with the aim of controlling severe sepsis was not longer popular: fecal diversion was thought to limit peritonitis and surgeons avoided source control in fear of spreading infection. In the 50's such 'palliative' operations were increasingly considered as unsatisfactory. The resection of the inflamed colonic segment followed by an anastomosis was suggested as a more 'bold' alternative. The improvement of anesthetic techniques and antibiotic therapy supported this approach of "eliminating the source of sepsis", as stated by Crile in 1954 or "source control" as later coined by Marshall $[120,121]$. It seems that a direct approach to the source of contamination, with diversion or resection of diseased segments, drainage of abscess, and suction of most of the pus and feces from abdominal cavity, gave the patient the best chance of survival [120]. Also during this period PRA with or without proximal protective colostomy was increasingly reported [32-35]. The results were good in the presence of a minimum peri-diverticular contamination or intra-mesenteric abscess [34].

The gold standard surgical treatment of complicated diverticulitis was the three-stage procedure with the drainage and colostomy as first stage. Stauton and Smiley supported the diversion of the perforated loop with sigmoid colostomy in the left iliac fossa plus drainage and colostomy $[49,50,59-61]$. Transverse colostomy was discouraged for fecal peritonitis as it might leave fecal residue proximal to the perforation [122]. Certainly the septic focus was removed from the peritoneal cavity, but the toxins were not removed from the circulation and still exerted their systemic effect $[123,124]$.

During the 1970s HP gained renewed popularity, because eradicating the source of sepsis had proved its superiority to mere diversion in terms of mortality and complications. Subsequent colostomy closure became an increasingly routine procedure, well standardized and progressively feasible [5, 84-113].

In the $1980 \mathrm{~s}$ a landmark systematic review by Krukowski and Matheson was published [125]. The two authors examined the mortality in 36 case series (821 cases of diverticulitis associated with purulent or fecal peritonitis) published between 1957 and 1984 that compared resection versus colostomy without resection. All patients underwent emergency surgery: mortality was $12 \%$ in the 316 who underwent resection versus $29 \%$ in the 505 who underwent colostomy without resection. Although there was a high risk of selection bias (patients in better health were more likely to undergo resection while patients with poor health status were more likely to receive a colostomy), this report found that, with antibiotics and better fluid resuscitation therapy, a substantial number of patients could undergo resection as an emergency procedure with an acceptable mortality rate. In addition, advocates of resection argued that emergency colectomy avoided the risk of missing colonic cancer (which was estimated to occur in $2-7 \%$ of the cases) and decreased morbidity [125].

The 1990s saw the emergence of two-stage resection and HP supported by two RCTs published in Denmark and France $[126,127]$. Kronborg, in a single-center study published in 1993, examined 62 patients operated on for diverticulitis complicated with peritonitis, 46 of whom were classified as Hinchey III (purulent peritonitis). Twenty-one were randomized to transverse colostomy, suture and omentoplasty without resection with 100\% survival. Six of the 25 patients $(24 \%)$ randomized to 
acute resection without primary anastomosis died postoperatively [126]. Kronborg concluded that simple suture of the perforation and omentoplasty with proximal diversion was safer and more effective than acute resection in purulent peritonitis and comparable in effectiveness [126]. Hospital stay was shorter and there were fewer inflammatory relapses after acute resection. Twenty-seven different surgeons operated on the 62 enrolled patients during 14 years. This RCT was suspended early due to slow recruitment (an average of four patients each year) and used subgroup analysis without statistical adjustment, and consequently lacked statistical power [126]. In contrast, the French multicenter prospective RCT included 103 patients with either purulent (Hinchey III) or fecal peritonitis (Hinchey IV) [127]. The primary endpoint was post-operative peritonitis. For the 48 patients who were randomized to colostomy (with perforation closure by suture in the Hinchey IV cases), the postoperative peritonitis rate was high, up to $20 \%$. In contrast, for the other 55 patients randomized to HP emergency resection, the postoperative peritonitis rate was significantly lower, less than $2 \%$. Three studies were published from 1985 to 2000 where the HP was compared to the three-stage technique (Table 6) $[126,128,129]$. Our recent meta-analysis of these three studies analyzed the overall mortality as the primary outcome [130]. A total of 159 patients had colonic resection versus 105 who maintained perforated diseased segment of colon after proximal diversion or suture of the colon perforation. Overall, mortality was $13.6 \%(20 / 147)$ in the colonic resection group versus $24.6 \%$ (18/73) after proximal diversion or suture of the colon perforation (with perforated diseased segment of colon maintained). Statistical analysis failed to show a statistically significant lower overall perioperative mortality rate in the colonic resection group compared to the other group (OR 0.53 , 95\% CI 0.16 to $0.73, P=0.31$ ) and heterogeneity among the included studies was high $\left(\mathrm{Tau}^{2}=0.71, \mathrm{Chi}^{2}=5.31, \mathrm{I}^{2}=62 \%\right)$ [130]. In 2000, the American Society of Colon and Rectal Surgeons based on expert review of the evidence concluded that segmental colonic resection followed by an end colostomy (i.e., HP) was the most suitable procedure for perforated diverticulitis with peritonitis [131].

During this period a number of systematic reviews and meta-analysis were published comparing PRA versus HP (Table 7) [130, 132-135].

The first published was Salem's review in 2004 [132]. This review identified 98 studies (published between 1957 and 2003) on the surgical management of perforated diverticulitis complicated with peritonitis. Perioperative mortality data from patients with diverticular peritonitis undergoing HP $(n=1,051)$ was calculated for 54 studies. Overall cumulative mortality rate was $19.6 \%$ (18.8\% for HP and $0.8 \%$ for subsequent procedures to restore intestinal continuity). The surgical site infection rate was $29.1 \%$ (24.2\% for HP and $4.9 \%$ for reversal). Stoma complications and anastomotic leaks (after restoring intestinal continuity) occurred in $10.3 \%$ and $4.3 \%$, respectively. Of 569 reported cases of PRA from 50 studies, the associated mortality rate was 9.9\% (range $0-75 \%)$ with an anastomotic leak rate of $13.9 \%$ (range, 0-60\%) and a surgical site infection rate of 9.6\% (range, 0-26). In patients with diverticular peritonitis who underwent PRA the reported mortality and morbidity rates were not higher than those in patients undergoing HP, suggesting that PRA was a safe operative option in this specific population.

However, in 2006, Constantinides et al. published a systematic review of 15 observational studies (13 retrospectives and 2 prospective nonrandomized studies published from 1984 to 2004) comparing PRA with HP for acute diverticulitis in emergency surgery [133]. They found that peri-operative mortality was lower in those patients who underwent PRA compared with those who underwent HP. In addition, there was a trend favoring PRA for surgical complications (surgical site infections, abscesses, and peritonitis). However, it has to be borne in mind that this review was at high risk of selection bias because of the primarily retrospective character of case series Notwithstanding, these data showed that: 1)

Table 6 Hartman procedure vs to three stages technique

\begin{tabular}{|c|c|c|c|c|c|c|c|c|c|}
\hline & \multirow{3}{*}{$\begin{array}{l}\text { Study } \\
\text { type }\end{array}$} & \multirow{2}{*}{\multicolumn{2}{|c|}{ Cases }} & \multirow[t]{3}{*}{ Age (yr) } & \multirow[t]{3}{*}{ Pathology } & \multicolumn{4}{|c|}{ Hinchey stage } \\
\hline & & & & & & \multicolumn{2}{|c|}{ Hinchey $</=2$} & \multicolumn{2}{|c|}{ Hinchey > 2} \\
\hline & & Resection & $\begin{array}{l}\text { Trasverse colostomy } \\
\text { and drainage }\end{array}$ & & & resection & $\begin{array}{l}\text { colostomy } \\
\text { and drainage }\end{array}$ & resection & $\begin{array}{l}\text { colostomy } \\
\text { and drainage }\end{array}$ \\
\hline $\begin{array}{l}\text { Nagorney et al. } \\
\text { (1985) }\end{array}$ & $\mathrm{R}$ & 90 & 31 & $\begin{array}{l}\text { CR } 61 \text { vs } \\
\text { TCD } 65\end{array}$ & $P$ & - & - & 90 & 31 \\
\hline $\begin{array}{l}\text { Finlay et al. } \\
\text { (1987) }\end{array}$ & $\mathrm{R}$ & 38 & 40 & $\mathrm{D}$ & $P, A$ & 12 & 29 & 26 & 11 \\
\hline $\begin{array}{l}\text { Kronborg et al. } \\
\text { (1993) }\end{array}$ & $\mathrm{RCT}$ & 31 & 31 & $\begin{array}{l}\text { CR } 73 \text { vs } \\
\text { TCD } 71\end{array}$ & $P$ & - & - & 31 & 31 \\
\hline
\end{tabular}

$R C T$ randomized controlled trial, $R$ retrospective observational trial $C R$ colon resection, TDC transverse colostomy and drainage

Pathology: $P$ peritonitis, $A$ abscess; $O$ obstruction, $D D$ diverticular disease 
Table 7 Systematic review: primary resection with anastomosis vs Hartmann's procedure

\begin{tabular}{|c|c|c|c|c|}
\hline Authors & Type of review & $\begin{array}{l}\text { Number of } \\
\text { studies included }\end{array}$ & $\begin{array}{l}\text { Number of } \\
\text { patients } \\
\text { included }\end{array}$ & Conclusion \\
\hline Salem 2004 & systematic review & 98 & 1.051 & $\begin{array}{l}\text { "Reported mortality and morbidity in patients with diverticular } \\
\text { peritonitis who underwent primary anastomosis were not } \\
\text { higher than those in patients undergoing Hartmann's procedure } \\
\text { were. This suggests that primary anastomosis is a safe operative } \\
\text { alternative in certain patients with peritonitis. Despite inclusion } \\
\text { of only patients with peritonitis in this analysis, selection bias may } \\
\text { have been a limitation and a prospective, randomized trial is } \\
\text { recommended." }\end{array}$ \\
\hline Constantinides 2006 & $\begin{array}{l}\text { systematic review } \\
\text { and metanalysis }\end{array}$ & 15 & 963 & $\begin{array}{l}\text { "Patients selected for primary resection and anastomosis have a } \\
\text { lower mortality than those treated by Hartmann's procedure in } \\
\text { the emergency setting and comparable mortality under conditions } \\
\text { of generalized peritonitis (Hinchey }>2 \text { ). The retrospective nature of } \\
\text { the included studies allows for a considerable degree of selection } \\
\text { bias that limits robust and clinically sound conclusions. This analysis } \\
\text { highlights the need for high-quality randomized trials comparing } \\
\text { the two techniques }\end{array}$ \\
\hline Abbas 2007 & systematic review & 18 & 884 & $\begin{array}{l}\text { "This review suggests that surgical resection and primary anastomosis } \\
\text { in acute diverticulitis with peritonitis compares favourably with } \\
\text { Hartmann's procedure in terms of peri-operative complications. } \\
\text { The need for revision of Hartmann's procedure could be subsequently } \\
\text { avoided. Some articles showed that patients with severe peritonitis, } \\
\text { who had a diverting stoma, in the setting of resection and primary } \\
\text { anastomosis, had the lowest complication rate. However, the quality } \\
\text { of these studies was poor with the presence of selection bias." }\end{array}$ \\
\hline Cirocchi 2013 & $\begin{array}{l}\text { systematic review } \\
\text { and metanalysis }\end{array}$ & 14 & 1041 & $\begin{array}{l}\text { "Despite numerous published articles on operative treatments for patients } \\
\text { with generalized peritonitis from perforated diverticulitis, we found a } \\
\text { marked heterogeneity between included studies limiting the possibility } \\
\text { to summarize in a meta-analytical method the data provided and make } \\
\text { difficult to synthesize data in a quantitative fashion. The advantages in } \\
\text { the group of colon resection with primany anastomosis in terms of lower } \\
\text { mortality rate and postoperative stay should be interpreted with caution } \\
\text { because of several limitations. Future randomized controlled trials are } \\
\text { needed to further evaluate different surgical treatments for patients with } \\
\text { generalized peritonitis from perforated diverticulitis." }\end{array}$ \\
\hline Lorusso 2016 & $\begin{array}{l}\text { systematic review } \\
\text { and metanalysis }\end{array}$ & 24 & 4.062 & $\begin{array}{l}\text { "Our meta-analysis shows that the PRA technique is better than HP for all } \\
\text { considered outcomes. Due to the high variability of the included studies, } \\
\text { further randomized controlled trials would be required to confirm } \\
\text { these results". }\end{array}$ \\
\hline
\end{tabular}

emergency PRA could be performed in selected cases with a low incidence of anastomotic leak (roughly 6\%); 2) PRA and HP had similar operative times; and 3) for the most severe cases (Hinchey IV), PRA and the HP had similar mortality (14.1 vs. $14.4 \%)$.

In 2006, the American Society of Colon and Rectal Surgeons updated their guidelines for the treatment of sigmoid diverticulitis dating from 2000 [136]. Emergency sigmoid resection was deemed mandatory for diverticulitis with peritonitis, and the alternatives to the HP consisted of PRA with or without a de-functioning stoma. The role of the PRA (particularly without the use of a de-functioning stoma) remained unclear.

In 2007, Abbas published a systematic review of trials conducted between 1966 and 2003 [134]. Eighteen nonrandomized studies reporting on 884 matched patients with complicated diverticulitis were included. There were no significant differences found between PRA and HP in terms of mortality, morbidity, sepsis, surgical site complications, duration of operation or antibiotic therapy. However, again the risk of selection bias was high.

Successively a RCT comparing PRA and HP was published [137]. The study protocol called for a de-functioning ileostomy within the PRA procedure. Ninety patients were randomized to PRA or HP in 14 centres in eight countries during a 9-year period [137]. Thirtyfour PRA patients were compared to $56 \mathrm{HP}$ patients. There were no statistically significant differences found in terms of age $(P=0.481)$, gender $(P=0.190)$, Hinchey stage III and IV $(P=0.394)$ and Mannheim Peritonitis Index $(P=0.145)$. There were no statistically significant differences found in mortality (2.9 vs. 10.7\%; $P=0.247$ ) or morbidity ( 35.3 vs. $46.4 \% ; P=0.38$ ) after PRA or HP. The rate of restoration of intestinal continuity was similar in both groups $(64.7 \%$ after PRA and $60 \%$ after HP, $P=0.659)$ after a similar lag 
time between emergency operation and elective stoma reversal $(P=0.43)$. The main difference between the two groups was the post-operative complication rate after restoration of intestinal continuity that differed statistically significantly ( 4.5 vs. $23.5 \%$ after PRA and HP, respectively; $P=0.05$ ). However, it is impossible to draw firm conclusions from this RCT because of early termination and enrolment of only $15 \%$ of its calculated sample size (600 patients to achieve $90 \%$ power to detect $10 \%$ difference in mortality).

Another systematic review and meta-analysis on the same topic, published in 2013, compared PRA and HP [130] for the treatment of diverticulitis complicated by peritonitis, including the above mentioned RCT [137]. The overall morbidity rate was $17 \%(40 / 235)$ and $28.37 \%(84 / 296)$ in the PRA and HP groups, respectively (OR $0.46,95 \%$ CI 0.23 to $0.90, P=0.02$ ). The reintervention rate after PRA did not differ significantly between the two groups $(15.2 \%$ versus $24.1 \%$ in the PRA and $\mathrm{HP}$, respectively; OR $1.06,95 \% \mathrm{CI} 0.24$ to $4.73, P=$ 0.94). Successively another RCT was published on this topic; Oberkofler and colleagues randomized 62 patients in four centres with acute perforation of left colon (Hinchey III and IV) to HP $(n=30)$ or PRA (with de functioning ileostomy, $n=32$ ) with a planned procedure to restore intestinal continuity after 3 months in both groups [138]. Both groups were similar at baseline (Hinchey III: $76 \%$ vs. $75 \%$ and Hinchey IV: $24 \%$ vs. $25 \%$, for HP vs. PRA respectively). The primary outcome was the overall complication rate that was similar in both groups $(80 \%$ vs. $84 \%$, $P=0.813)$. The outcomes after the primary colon resection were also similar (mortality $13 \%$ vs. 9\% and morbidity $67 \%$ vs. $75 \%$ in HP vs. PRA). This is the first RCT that seems to favour PRA in patients with complicated diverticulitis with peritonitis. However, there is evidence of bias, as highlighted by Panis in his comments, therefore no firm conclusions can be drawn [139]. Succesively Lorusso published a systematic review including 24 studies, in [135] which reported the same our results (Table 8) [137, 138, 140-162].

Recently laparoscopic peritoneal lavage (LPL) with drainage and antibiotics has been recently introduced into the surgical practice with aim to decrease the rate of HP [163, 164]. In 2009, Toorenvliet's systematic review identified 231 patients with acute diverticulitis who underwent LPL, drainage and antibiotics therapy [165]. In $95.7 \%$ of patients this minimally invasive procedure permitted adequate control of the abdominal and systemic sepsis, with low rates of mortality (1.7\%), morbidity (10.4\%) and stoma (1.7\%). Most patients subsequently had a delayed elective laparoscopic PRA. Patients who did not undergo subsequent resection had a long recurrence free period. The authors concluded that LPL was an effective and safe treatment of peritonitis secondary to perforated diverticulitis [165].
However, the use of peritoneal lavage without primary resection in generalized peritonitis originating from perforated diverticulitis remains controversial. Recently three RCT (DILALA-trial, SCANDIV-trial, LADIES trial) including a total of 343 participants (178 in the lavage group versus 175 in the resection group) have been published on this topic (Table 9) [166-168].

The DILALA trial included patients with only Hinchey III peritonitis diagnosed by laparoscopy and with 1-year re-operation rate as primary outcome. The preliminary analysis of the short-term results (12 weeks) in 76 patients reported no statistically significant difference regarding morbidity and mortality, statistically significant longer period of abdominal drainage but shorter hospital stay in the LPL group compared to HP group [167].

LADIES was a two-arm trial with 1-year morbidity and mortality as the primary outcome. The LOLA arm compared laparoscopic lavage with sigmoidectomy in 90 patients with Hinchey III diverticulitis [166]. The trial could not prove the superiority of LPL and was terminated due to increased adverse events in this group despite the lack of statistical significance.

In contrast, the SCANDIV trial was able to report on the totality of 199 patients randomized to laparoscopic lavage or to laparoscopic/open resection with or without anastomosis [168]. The primary outcome was 90-day major complications rate according to the ClavienDindo classification. The authors reported a nonstatistically significant higher incidence of the primary outcome in the LPL group and comparable mortality. However, there were statistically significantly higher rate of abscesses, secondary peritonitis and re-operations and in the LPL group along with missed malignancy in four cases. Despite the shorter operative time in the LPL group (72 vs $149 \mathrm{~min}$ ), the hospital stay was similar in both groups. However, the study has several limitations such as inclusion of patients with Hinchey I and II and participation of more experienced surgeons in the resection group, which might be a source of significant bias [169].

Slim recently published a letter in which the three RCTs were examined and none showed laparoscopic lavage to be superior. In relation to three metaanalysis of these studies could respond to the question raised by this editorial, but "... came to opposite conclusions....." [170].

We published the fourth meta-analysis, that failed to demonstrate significant benefits (Table 10) [171-174]. Overall the quality of evidence was low because of serious concern regarding the risk of bias and imprecisions. A significantly increased rate of intra-abdominal abscess formation $(\mathrm{RR}=2.54,95 \% \mathrm{CI} 1.34$ to 4.83 ) (moderate 
Table 8 Evidence about primary resection with anastomosis vs Hartmann's procedure

\begin{tabular}{|c|c|c|c|c|c|c|c|c|}
\hline & \multirow{3}{*}{$\begin{array}{l}\text { Study } \\
\text { type }\end{array}$} & \multirow{2}{*}{\multicolumn{2}{|c|}{ Cases }} & \multirow[t]{3}{*}{ Pathology } & \multicolumn{4}{|c|}{ Hinchey stage } \\
\hline & & & & & \multicolumn{2}{|c|}{ Hinchey $</=2$} & \multicolumn{2}{|c|}{ Hinchey $>2$} \\
\hline & & PRA & $\mathrm{HP}$ & & PRA & HP & PRA & HP \\
\hline Hold et al. (1990) & $\mathrm{R}$ & 99 & 76 & $D D, P, A$ & 83 & 45 & 16 & 31 \\
\hline Gooszen et al. (2001) & R & 32 & 28 & $D D, P, A$ & 11 & 9 & 21 & 19 \\
\hline Schilling et al. (2001) & PNR & 13 & 42 & $\mathrm{DD}, \mathrm{P}$ & 0 & 0 & 13 & 42 \\
\hline Regenet et al. (2003) & PNR & 27 & 33 & $\mathrm{DD}, \mathrm{P}$ & 0 & 0 & 27 & 33 \\
\hline Richter et. Al (2006) & PNR & 36 & 5 & $D D, P$ & 0 & 0 & 36 & 5 \\
\hline Trenti et al. (2011) & $\mathrm{R}$ & 27 & 60 & $P$ & 0 & 0 & 58 & 69 \\
\hline Oberkofler et al. (2012) & $\mathrm{RCT}$ & 32 & 30 & (DD) $P$ & 0 & 0 & 32 & 30 \\
\hline Alanis et al. (1989) & $\mathrm{R}$ & 34 & 26 & $D D, P, A$ & 31 & 19 & 3 & 7 \\
\hline Alizai (2013) & $\mathrm{R}$ & 26 & 72 & $D D, P, A$ & 16 & 24 & 10 & 48 \\
\hline Blair (2002) & $\mathrm{R}$ & 33 & 634 & $D D, P, A$ & 24 & 31 & 9 & 32 \\
\hline Berry (1989) & $\mathrm{R}$ & 27 & 47 & $\mathrm{DD}, \mathrm{P}, \mathrm{A}, \mathrm{O}, \mathrm{F}, \mathrm{B}$ & NR & NR & NR & NR \\
\hline Gawlick (2012) & R & 340 & 1678 & $\mathrm{DD}, \mathrm{P}, \mathrm{A}$ & NR & NR & NR & NR \\
\hline Herzog (2011) & R & 21 & 19 & $\mathrm{DD}, \mathrm{P}, \mathrm{A}, \mathrm{O}, \mathrm{B}$ & $N R$ & NR & NR & NR \\
\hline Kourtesis (1988) & R & 23 & 10 & $D D, P, A, F$ & $N R$ & 6 & 0 & 4 \\
\hline Mäkelä (2005) & R & 64 & 93 & $\mathrm{DD}, \mathrm{P}$ & 62 & 19 & 2 & 0 \\
\hline Mueller (2011) & R & 47 & 26 & $\mathrm{DD}, \mathrm{P}, \mathrm{A}$ & 45 & 14 & 2 & 12 \\
\hline Pastenak (2010) & R & 46 & 65 & $\mathrm{DD}, \mathrm{P}, \mathrm{A}$ & 34 & 17 & 12 & 48 \\
\hline Saccomani (1993) & R & 26 & 8 & $\mathrm{DD}, \mathrm{P}, \mathrm{A}, \mathrm{F}$ & $N R$ & NR & $N R$ & NR \\
\hline Smirniotis (1992) & R & 6 & 18 & $\mathrm{DD}, \mathrm{P}, \mathrm{A}$ & 6 & 10 & 0 & 8 \\
\hline Stumpf (2007) & R & 36 & 30 & $D D, P, A, O$ & NR & NR & NR & NR \\
\hline Tabbara (2010) & R & 18 & 176 & $D D, P, A, S$ & 16 & 69 & 2 & 107 \\
\hline Zingg et al. (2009) & PNR & 46 & 65 & $D D, P$ & 34 & 17 & 12 & 48 \\
\hline Binda et al. (2012) & RCT & 34 & 56 & $P$ & 0 & 0 & 34 & 56 \\
\hline Tudor (1994) & PNR & 76 & 77 & $\mathrm{DD}, \mathrm{P}, \mathrm{A}, \mathrm{B}, \mathrm{O}, \mathrm{F}$ & 29 & 20 & 8 & 44 \\
\hline Vermeulen (2007) & $\mathrm{R}$ & 61 & 139 & $\mathrm{DD}, \mathrm{P}, \mathrm{A}$ & 35 & 44 & 26 & 95 \\
\hline
\end{tabular}

$R C T$ randomized controlled trial, $P N R$ prospective, nonrandomized, $R$ retrospective PRA primary resection and anastomosis, HP Hartmann's operation

Pathology: $P$ peritonitis, $A$ abscess, $O$ obstruction, $D D$ diverticular disease

$F$ fistula, $B$ bleeding (dc chronic diverticulitis)

quality of evidence), was seen with this approach. However, LPL does not appear inferior to traditional surgical resection and may achieve reasonable outcomes (lower rate of post-operative wound infections, $\mathrm{R}=0.10,95 \% \mathrm{CI}$ 0.02 to 0.51 ) and less hospital resources (shorter duration of post-operative hospital stay during index admission, $\mathrm{WMD}=-2.03,95 \% \mathrm{CI}-2.59$ to -1.47$)$.

\section{Discussion}

This review analyzes the best scientific evidence for over a century of surgery for complicated DD stratifying the technical solutions over time.

It is difficult to draw firm conclusions based on the available evidence. The studies were principally retrospective and prone to bias, irrespective of the decade in question. Also the few currently available RCTs have limitations and therefore have not been able to provide clear recommendations.

Since the publication of Graser in 1899, DD has been a subject of increasing interest for clinicians and surgeons [175]. DD is more frequent in Western countries (especially left-sided) and a trend toward increased frequency has been noted with estimated prevalence of 20-60\% [176].

Despite the intensive research since the beginning of the last century, decisions regarding if and when to operate on patients with diverticulitis remains a topic of substantial debate. The debate between supporters of non-operative and traditional techniques has existed over this time and persists to this day. However, no 


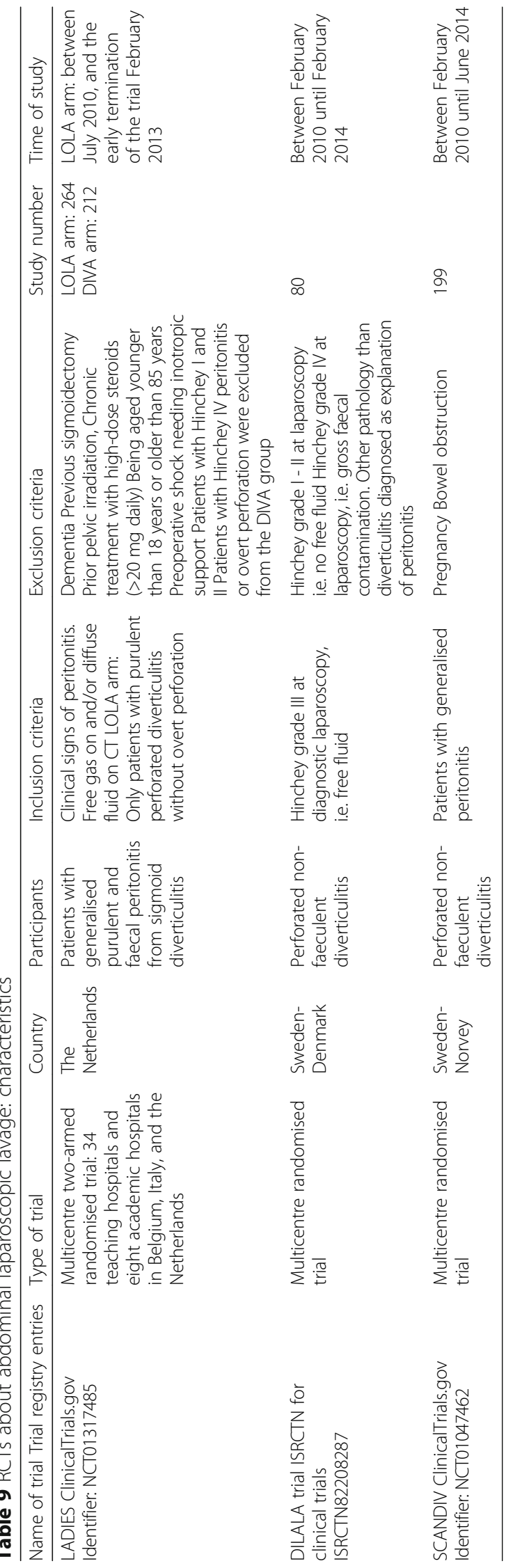


Table 10 Meta-analysis about laparoscopic abdominal lavage

\begin{tabular}{|c|c|c|c|c|c|}
\hline & \multicolumn{2}{|l|}{ Cirocchi } & \multirow{2}{*}{$\begin{array}{l}\text { Ceresoli } \\
\text { Hinchey III }\end{array}$} & \multirow{2}{*}{$\begin{array}{l}\text { Angenete } \\
\text { Hinchey III }\end{array}$} & \multirow{2}{*}{$\begin{array}{l}\text { Marshall } \\
\text { Hinchey III }\end{array}$} \\
\hline & All Hinchey & Hinchey III & & & \\
\hline $\begin{array}{l}\text { Post-operative mortality at } \\
\text { index admission or within } \\
30 \text { days from index } \\
\text { intervention }\end{array}$ & $\begin{array}{l}\text { RR } 1.33,95 \% \mathrm{Cl} \\
0.37 \text { to } 4.74\end{array}$ & $\begin{array}{l}\text { RR } 3.01,95 \% \mathrm{Cl} \\
0.48 \text { to } 18.93\end{array}$ & $\begin{array}{l}\text { OR } 0.93 ; 95 \% \text { C.I. } \\
0.23-3.82 ; P=0.92\end{array}$ & RR $1.34,95 \%$ Cl 0.59-3.04 & $\begin{array}{l}\text { RR } 1.34,95 \% \mathrm{Cl} \\
0.37 \text { to } 4.79\end{array}$ \\
\hline Mortality at 90 days & $\begin{array}{l}\text { RR } 1.27,95 \% \mathrm{Cl} \\
0.60 \text { to } 2.69\end{array}$ & Not performed & $\begin{array}{l}\text { OR } 0.83 ; 95 \% \text { C.I. } \\
0.32-2.11 ; P=0.69\end{array}$ & RR $0.86,95 \%$ Cl 0.40-1.83 & $\begin{array}{l}\text { RR } 0.86,95 \% \mathrm{C} \\
0.40 \text { to } 1.84\end{array}$ \\
\hline Mortality at 12 months & $\begin{array}{l}\text { RR } 0.84,95 \% \mathrm{Cl} \\
0.38 \text { to } 1.88\end{array}$ & Not performed & OR $0.74 P=0.51$ & RR $0.54,95 \%$ Cl $0.38-0.76$ & \\
\hline $\begin{array}{l}\text { Reoperation at index } \\
\text { admission or within } \\
30 \text { days from index } \\
\text { intervention }\end{array}$ & $\begin{array}{l}\text { RR } 1.93,95 \% \mathrm{Cl} \\
0.71 \text { to } 5.22\end{array}$ & $\begin{array}{l}\mathrm{RR}=1.40,95 \% \mathrm{Cl} \\
0.71 \text { to } 4.90\end{array}$ & OR $3.75, P=0.006$ & RR $1.34,95 \%$ Cl 0.59-3.04 & $\begin{array}{l}\text { RR } 3.03,95 \% \mathrm{C} \\
1.16 \text { to } 7.89\end{array}$ \\
\hline $\begin{array}{l}\text { At } 90 \text { days follow } \\
\text { reoperations }\end{array}$ & Not analyzed ${ }^{a}$ & Not performed & NR & RR 1.71, 95\% Cl 0.85-3.43 & NR \\
\hline $\begin{array}{l}\text { At } 12 \text { months follow } \\
\text { reoperations }\end{array}$ & $\begin{array}{l}\text { RR } 0.57,95 \% \mathrm{Cl} \\
0.39 \text { to } 0.86\end{array}$ & Not performed & OR $0.32, P=0.0004$ & RR $0.54,95 \%$ Cl $0.38-0.76$ & NR \\
\hline $\begin{array}{l}\text { Intra-abdominal abscesses } \\
\text { at index admission or } \\
\text { within } 30 \text { days from } \\
\text { index intervention }\end{array}$ & Not analyzed ${ }^{\mathrm{b}}$ & Not performed & $\begin{array}{l}\text { OR 3.50; 95\% C.I. } \\
1.79-6.86 ; P=0.0003\end{array}$ & NR & NR \\
\hline $\begin{array}{l}\text { Intra-abdominal abscesses } \\
\text { at } 90 \text { days }\end{array}$ & $\begin{array}{l}\mathrm{RR}=2.54,95 \% \mathrm{Cl} \\
1.34 \text { to } 4.83\end{array}$ & Not performed & NR & NR & NR \\
\hline Wound infections & $\begin{array}{l}\mathrm{RR}=0.10,95 \% \mathrm{Cl} \\
0.02 \text { to } 0.51\end{array}$ & Not performed & $\begin{array}{l}\text { OR } 0.14 ; 95 \% \text { C.I. } \\
0.04-0.45 ; P=0.0009\end{array}$ & NR & NR \\
\hline Morbidity at 90 days & Not performed & Not performed & $\begin{array}{l}\text { OR 1.70; 95\% C.I. } \\
1.00-2.87 ; P=0.05\end{array}$ & NR & NR \\
\hline $\begin{array}{l}\text { Presence of stoma at } \\
12 \text { months }\end{array}$ & $\begin{array}{l}\mathrm{RR}=0.50,95 \% \mathrm{Cl} \\
0.14 \text { to } 1.75\end{array}$ & Not performed & OR $0.44 P=0.27$ & NR & $\begin{array}{l}\text { RR } 0.50,95 \% \mathrm{C} \\
0.14 \text { to } 1.76\end{array}$ \\
\hline Operating time & Not analyzed ${ }^{c}$ & Not performed ${ }^{j}$ & NR & NR & NR \\
\hline $\begin{array}{l}\text { Post-operative persistent } \\
\text { peritonitis }\end{array}$ & Not analyzed ${ }^{d}$ & Not performed & NR & NR & NR \\
\hline $\begin{array}{l}\text { Post-operative secondary } \\
\text { peritonitis }\end{array}$ & Not analyzed ${ }^{e}$ & Not performed & NR & NR & NR \\
\hline $\begin{array}{l}\text { Length of post-operative } \\
\text { hospital stay during index } \\
\text { admission. }\end{array}$ & $\begin{array}{l}\text { WMD }-2.03,95 \% \\
\text { Cl-2.59 to- }-1.47\end{array}$ & Not performed ${ }^{j}$ & NR & NR & NR \\
\hline $\begin{array}{l}\text { Adverse events within } \\
90 \text { days by Dindo-Clavien } \\
\text { grade I-II }\end{array}$ & Not analyzed ${ }^{f}$ & Not performed ${ }^{j}$ & NR & NR & NR \\
\hline $\begin{array}{l}\text { Adverse events within } \\
90 \text { days by Dindo-Clavien } \\
\text { grade Illa }\end{array}$ & Not analyzed ${ }^{9}$ & Not performed & NR & NR & NR \\
\hline $\begin{array}{l}\text { Adverse events within } \\
90 \text { days by Dindo-Clavien } \\
\text { grade IIlb }\end{array}$ & $\begin{array}{l}\text { RR } 1.40,95 \% \mathrm{Cl} \\
0.47 \text { to } 4.17\end{array}$ & Not performed & NR & RR $1.46,95 \%$ Cl 0.99-2.20 & NR \\
\hline $\begin{array}{l}\text { Adverse events within } \\
90 \text { days by Dindo-Clavien } \\
\text { grade IVa }\end{array}$ & $\begin{array}{l}\text { RR } 0.59,95 \% \mathrm{Cl} \\
0.20 \text { to } 1.75\end{array}$ & Not performed ${ }^{j}$ & NR & NR & NR \\
\hline $\begin{array}{l}\text { Adverse events within } \\
90 \text { days by Dindo-Clavien } \\
\text { grade IVb }\end{array}$ & $\begin{array}{l}\text { RR } 0.62,95 \% \mathrm{Cl} \\
0.10 \text { to } 3.75\end{array}$ & Not performed & NR & NR & NR \\
\hline $\begin{array}{l}\text { Total length of hospital } \\
\text { stays within } 12 \text { months. }\end{array}$ & Not analyzed ${ }^{h}$ & Not performed & NR & NR & NR \\
\hline \multirow[t]{2}{*}{ Quality of Life } & Not analyzedi & Not performed & NR & NR & NR \\
\hline & NR & NR & NR & NR & \\
\hline
\end{tabular}


Table 10 Meta-analysis about laparoscopic abdominal lavage (Continued)

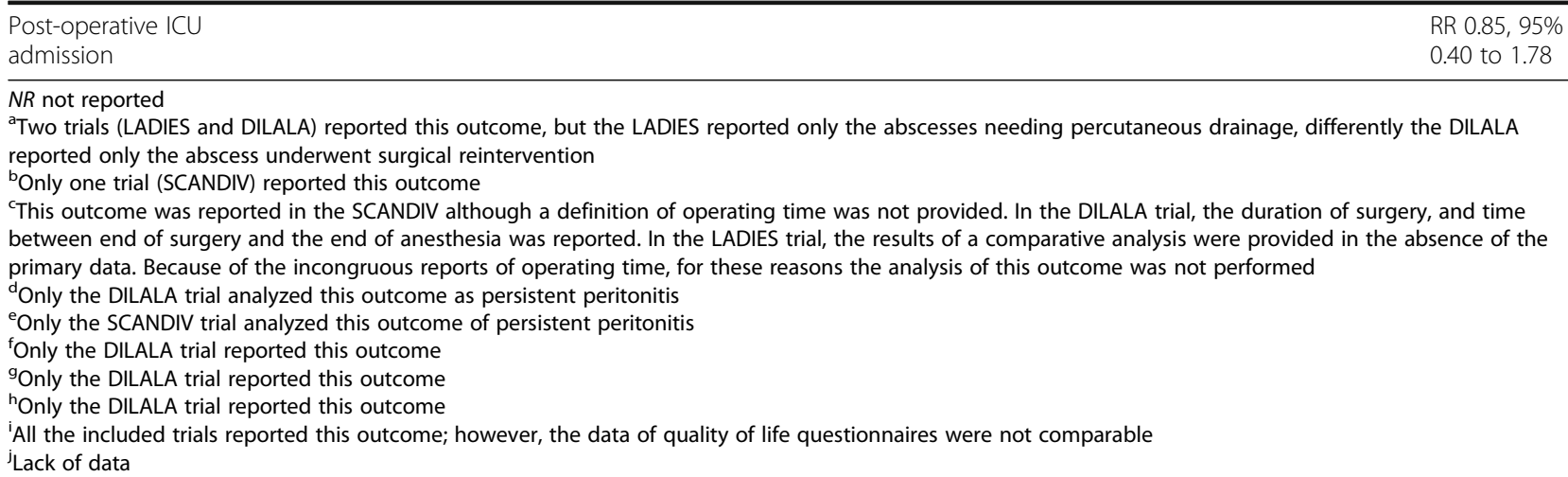

single treatment strategy has dominated in terms of efficacy or safety.

Diverticulitis is complicated in approximately $10-25 \%$ of all cases. Operations are traditionally reserved for complicated diverticulitis (colon perforation and peritonitis, abscess, fistula, or stenosis). After a first acute attack of diverticulitis, approximately $20-30 \%$ of patients undergo surgery, around a half of these cases being performed as an emergency. Of these, $15-40 \%$ tend to be young patients (less than 50 years old). The mortality of emergency operations is between 10 and $20 \%$ while in elective surgery it is less than 2\% [177] The condition has a great social and financial impact. In USA about 313.000 hospitalizations are due to diverticular disease with more 50.000 bowel resections annually $[178,179]$.

A retrospective cost analysis from USA found that treatment of DD for 1 financial year was $5.3 \%$ of the total annual budget of General Surgery [180]. At present, diverticulitis is the associated diagnosis for one third of all colostomies and/or colon resections [132].

Recent literature has reported an increase in the incidence of DD among younger patients. In a large review of the Nationwide Inpatient Sample (NIS) of 267,000 admissions for AD between 1998 and 2005, incidence rates increased dramatically in 18 to 44 year-olds and 45 to 64 year-olds, while they remained stable in 65 to 74 year-olds and actually decreased in persons 75 years of age or older [181].

Generally, more aggressive treatments have been used in patients in better health with less aggressive options reserved for patients in a poor state of health. Therefore, direct comparisons between such treatments in an observational study setting could lead to the erroneous conclusion that the more aggressive interventions are associated with lower morbidity and mortality than the conservative options.

It is interesting to note that some of the oldest described therapeutic options, such as the peritoneal lavage and drainage or surgery in several stages, are still very relevant today. This is particularly true on the background of the new potent antimicrobial agents, improved ICU management, the wider use of percutaneous drainage and last, but not least due to the growing experience with laparoscopic surgery.

Antimicrobial therapy plays an important role in the management peritonitis from complicated acute diverticulitis. Judicious use of antibiotics should be considered an integral part of good clinical practice. It can maximize the utility and therapeutic efficacy of treatment, and minimize the risks associated with emerging infections and the selection of resistant pathogens. Antimicrobial therapy is typically empiric because critically-ill patients need immediate treatment and microbiological data usually requires more than 24/36 h for the identification of pathogens and antibiotic susceptibility pattern.

In the last years several guidelines have been published in literature in the setting of intra-abdominal infections [182-186]. However, consideration of local epidemiological data and regional resistance profiles should be essential for antibiotic selection.

Considering the intestinal micro biota, patients with acute diverticulitis requires antibiotics toward grampositive and gram-negative bacteria, as well as for anaerobes. Most of the complicated acute diverticulitis is community acquired infection. In these condition the main resistance threat in intra-abdominal infections may posed by Extended-Spectrum Beta-Lactamase (ESBL)-producing Enterobacteriaceae, which are becoming common in community-acquired infections worldwide [182]. The most significant risk factors for ESBL producing infection include prior exposure to antibiotics and co morbidities requiring concurrent antibiotic therapy [182].

The duration of therapy should be shortened as much as possible if there no signs of ongoing infections. Patients who have signs of sepsis beyond 5 to 7 days of treatment need diagnostic investigation to determine an ongoing uncontrolled source of infection [187].

In the management of critically ill patients with sepsis and septic shock clinical signs and symptoms as well as 
inflammatory response markers such as pro calcitonin, although debatable, may assist in guiding antibiotic treatment [187].

However, the variety of available treatments and the paucity of good quality evidence make clinical decision making difficult for surgeons especially in emergency setting.

Tracking the development of current surgical practice is very important due to several reasons. Firstly, we pay tribute to our teachers who paved the way to our current achievements. Secondly, analyzing historical procedures allows us to understand that these are still very relevant despite the technological advancements; we can still learn from them and further develop such techniques.

The treatment of complicated DD in the early decades was dominated either by only lavage with/without suture or different stage-procedures. In the 70's HP gradually became increasingly popular and a routine procedure with acceptable mortality and morbidity, probably due to higher rate of successful colostomy closure at the second stage. The period 1991-2000 is characterized by increased frequency of the re-sectional surgery but the first two RCTs reported controversial results. From 2001 until now there has been a marked shift in surgical practice toward PRA and wider use of the laparoscopic approach with or without resection. This is probably due to the growing recognition that Hartmann's reversal is not a benign procedure with $49-55 \%$ morbidity and $20 \%$ mortality rates [188-190]. Moreover, a large number of patients never undergo restoration (48-74\%), albeit that patients with diverticular disease have significantly higher reversal rate (83\%) [190, 191].

The studies published in 2001-2016 can be divided into two categories - comparing HP versus resection with PRA and those investigating the effectiveness of LPL, drainage and antibiotic therapy as an initial approach versus resection.

Several comparative studies published in this period reported improved outcome after resection with primary anastomosis in contrast to Hartmann's procedure such as those of Salem et al., Constantinides et al., whereas the work of Abbas et al. showed similar results with respect to morbidity and mortality rates, duration of the operation and antibiotic therapy [132-134]. Two RCTs directly compared PRA and HP. Binda et al. reported no significant difference in mortality and morbidity rates, but significantly lower complication rate after intestinal continuity restoration in PRA versus HP [137]. However, it was stopped due to insufficient recruitment rate. A other trial found similar complication rate [138]. A recent systematic review [130] found that despite the growing body of the literature there is a marked heterogeneity between studies, which precludes the possibility to draw valid conclusions. PRA was associated with lower, but insignificant mortality rate and significantly shortened hospital stay. Generally, the benefit of PRA seems to be of lower mortality rate and shorter postoperative stay. The studies failed to write a definitive word on this issue, because their premature conclusion and bias, and, for many reasons (the laparoscopic lavage procedure's widespread included), nowadays a study like this seems impractical.

The second group of studies has been dealing with the still controversial role of LPL with drainage and antibiotic therapy. Recently there has been a steady trend toward this approach as a definitive treatment or as bridge procedure to subsequent delayed resection due to the well-known advantages of the laparoscopic surgery and in order to reduce the rate of HP.

The systematic review of Toorenviliet et al. reported adequate control of the infection and successful delayed laparoscopic resection in most of the cases [165].

The more recent systematic review analyzed 19 studies on LPL with follow-up between 1.5 and 96 months. In $24 \%$ of the cases it was sufficient treatment with reintervention rate $5 \%$ and 30 -day mortality $4.8 \%$. Readmission rate was $7 \%$ with redo surgery in $69 \%$ of the cases of which $92 \%$ underwent PRA. In 36\% two-stage laparoscopic management was performed [192].

None recent RCT trials [166-168] did show any significant advantage of LPL with respect to post-operative mortality and surgical re-interventions. The overall picture seems to be mostly of equivalence, except for higher reoperation rates in the LPL group, as seen in two out of the three trials. It is noteworthy that re-operation after LPL in the prematurely terminated LADIES trial did not result in excess mortality. The SCANDIV study was strongly criticized by some due to several limitations such as inclusion of patients with Hinchey I and II and participation of more experienced surgeons in the resection group which may be sources of significant bias $[169,193]$.

Furthermore in early 1980 some authors reported the routine use of ureteral catheters to minimize the incidence of ureteral injury during colorectal surgery (from 0.2 to $4.5 \%$ ) [194-197]. In the following decades, with introduction of laparoscopic colectomy the prophylactic placement of ureteral catheters during colorectal surgery has been recommended for prevention of ureteral injuries [198, 199]; so some surgeons reported the use of lighted ureteral stents during colectomy [200]. In complicated diverticulitis the sigmoidectomy is a surgical challenge for the fibrotic adherences with the ureter. Moshe Schein reported that "Severely" plastered diverticulitis has been referred to by some as "malignant diverticulitis" and claimed to be a contra-indication to resection. Using an appropriate technique and staying "near the bowel" an experienced surgeon should be able to resect any sigmoid" [107, 201, 202]. It follow that in these complicated diverticulitis 
the prophylactic placement of ureteral catheters can reduce the ureteral injuries. The use of prophylactic ureteral catheters was reported in the surgical treatment of complicated diverticulitis, but the use of these catheters was performed only in election surgery and often during laparoscopic colectomy.

The last problem are the localized peritonitis, that not properly treated can evolve into an abdominal abscess, that are associated with an acute mortality of $5-10 \%$. Treatment of these abscess depends on size, localization and patient's general condition. Though solid supporting evidence is lacking, most abscess $\leq 3 \mathrm{~cm}$ in diameter are treated safely with antibiotics. For larger abscesses there is much evidence supporting the advantages of percutaneous drainage combined with antibiotics [203-205]. There is no evidence supporting a specific drainage or the aspiration technique. If an abscess cannot be drained percutaneously, an urgent surgical procedure is advised. Resection with primary anastomosis is the intervention of choice: there is increasing evidence that a drainage through a laparoscopic approach can be successful avoiding a further resection or deferiing it to an elective setting. After a successful percutaneous drainage of an abscess there is no agreement or evidence supporting a conservative or surgical policy [206].

Despite limitations due to the lack of strong evidence for the reasons discussed above, we summarize and propose a treatment for various clinical scenarios below:

- Patient in a good general condition with Hinchey I or II - Initially stabilize with medical treatment with or without percutaneous drainage; followed by elective PRA without protective stoma if required and/or suitable.

- Above scenario, but non-responder to initial management: two-stage procedure (emergency $\mathrm{HP}$ with or without a mucous fistula, followed by elective reversal if suitable) or PRA with or without a de functioning stoma.

- Selected cases Hinchey II-III - LPL.

- Hinchey III not suitable for LPL - PRA or HP.

- Hinchey IV - HP.

On this issue the results of two ongoing studies are waited: one RCT study, LapLand and one multicenter retrospective study on patients submitted to laparoscopic lavage, the LLOStudy $[207,208]$.

After preliminary promising results [209], future ongoing experiences might confirm the feasibility and demonstrate the safety of laparoscopy and primary anastomosis even in cases of selected, hemodynamically stable, patients with Hinchey IV perforated diverticulitis and feacal peritonitis, if performed by experienced colorectal surgeons [210].

\section{Conclusion}

The management of patients with colon perforation from diverticulitis is still evolving. During the late 19th century initial lavage with or without simple suture and drainage was the suggested treatment. The three-stage Mayo Clinic or the two-stage Mickulicz procedures gradually replaced this. Fears of inadequate control of the source of sepsis prompted the implementation of the resection of the affected segment of colon with formation of a colostomy (HP) in the 1970's. The future development of the treatment strategies was driven by the recognition of the high morbidity and mortality associated with HP and the low Hartmann's reversal rates. This led to the wider use of resection with PRA during the 1990's.

The technique of lavage and drainage regained its popularity during the 1960's. It has relatively recently become possible to perform this procedure laparoscopically which takes advantage of the benefits of minimally invasive surgery with faster recovery and shorter hospital stay. Using this strategy allows resection surgery to be postponed or avoided altogether in many patients; moreover, an higher rates of PRA can be achieved avoiding the need for a stoma. The three recent RCTs of LPL reported inconsistent outcomes. These findings warrant further research and debate.

\section{Acknowledgements}

We thank Alessandro Quintili for developing the search strategies and for the support in the research of full text.

Funding

None

Availability of data and materials

All datasets, tables and figures supporting the conclusions of this article are included within the article.

Authors' contributions

RC, SA, SDS, GAB were responsible for the study concept and design. RC and SA have written the manuscript, RC and SA carried out the literature search. All authors critically reviewed the manuscript for important intellectual content. AF and $G A B$ were the study supervisors. All authors read and approved the final version of the manuscript.

Competing interests

The authors declare that they have no competing interests.

Consent for publication

Not Applicable.

Ethics approval and consent to participate Not applicable.

\section{Strengths and limitations of this study}

To our knowledge, this is the first systematic and historical review on the surgical treatment of peritonitis from colonic diverticulitis' perforation.

This systematic review is based on the best evidence published in surgical journals from 1900 to the present day.

The arguments are reported in chronological order, stating how the operations (technique and peri-operative care) were influenced over time. Limitations of this review include the low level of evidence and the small sample sizes of the included studies.

Most of the studies were performed in Western countries, potentially reducing the external validity and the generalizability of the findings. 


\section{Author details}

'Department of General Surgery, University of Perugia, Terni Hospital, Terni, Italy. ${ }^{2}$ Department of General Surgery, Cumberland Infirmary, Carlisle, UK. ${ }^{3}$ General (Colorectal) Emergency and Trauma Surgery Service, Maggiore Hospital Regional Emergency Surgery and Trauma Center - Bologna Local Health District, Bologna, Italy. ${ }^{4}$ Military Medical Academy, Sofia, Bulgaria. ${ }^{5}$ Department of Surgery, Terni Hospital, Terni, Italy. ${ }^{6}$ Department of Surgery, University of Ferrara, Ferrara, Italy. 'Department of Surgery, Macerata Hospital, Macerata, Italy. ${ }^{8}$ Department of Emergency Surgery, Parma Hospital, Parma, Italy. ${ }^{9}$ Department of Surgery, Forlì Hospital, Forli, Italy. ${ }^{10}$ Department of Gastrointestinal and General Surgery, Medical University of Wrocław, Wrocław, Poland. ${ }^{11}$ Section for Surgical Research, Department of Surgery, Medical University of Graz, Graz, Austria. ${ }^{12}$ First Department of Surgery, Hippokration University Hospital, University of Athens, Athens, Greece. ${ }^{13}$ Department of Surgery, E.O. OspedaliGalliera, Genova, Italy.

\section{Received: 29 September 2016 Accepted: 1 February 2017} Published online: 09 March 2017

\section{References}

1. Jacobs DO. Diverticulitis. N Engl J Med. 2007;357(20):2057-66. doi:10.1056/ NEJMcp073228.

2. Stollman N, Raskin J. Diverticular disease of the colon. Lancet. 2004;21(363): 631-9. doi:10.1016/S0140-6736(04)15597-9.

3. Tursi A. New medical strategies for the management of acute diverticulitis. Expert Rev GastroenterolHepatol. 2015;9(10):1293-304. doi:10.1586/17474124. 2015.1075881.

4. Bullard Dunn KM, Rothenberger DA Diverticular disease. In: BrunicardiF, Andersen D (Eds). Schwartz's Principles of Surgery, 10th edition. 2014;1201-3.

5. Hinchey EJ, Schaal PG, Richards GK. Treatment of perforated diverticular disease of the colon. AdvSurg. 1978;12:85-109.

6. Kaiser AM, Jiang JK, Lake JP, Ault G, Artinyan A, Gonzalez-Ruiz C, Essani R, Beart RW. The management of complicated diverticulitis and the role of computed tomography. Am J Gastroenterol. 2005;100(4):910-7. doi:10.1111/ j.1572-0241.2005.41154.x.

7. Sher ME, Agachan F, Bortul M, Nogueras JJ, Weiss EG, Wexner SD. Laparoscopic surgery for diverticulitis. SurgEndosc. 1997;11:264-7. doi:10. 1007/s004649900340.

8. Kohler L, Sauerland S, Neugebauer E. Diagnosis and treatment of diverticular disease: results of a consensus development conference. The Scientific Committee of the European Association for Endoscopic Surgery. SurgEndosc. 1999;13(4):430-6. doi:10.1007/s004649901007.

9. Vermeulen J, Gosselink MP, Hop WC, Lange JF, Coene PP, Harst E, Weidema WF, Mannaerts GH. Hospital mortality after emergency surgery for perforated diverticulitis. Ned TijdschrGeneesk. 2009;153:1209-14.

10. Horiuchi A, Watanabe Y, Doi T, Sato K, Yukumi S, Yoshida M, Yamamoto Y, Sugishita H, Kawachi K. Evaluation of prognostic factors and scoring system in colonic perforation. World J Gastroenterol. 2007;13(23):3228-31. doi:10. 3748/wjg.v13.i23.3228.

11. Vincent J, De Mendoca A, Cantraine F, et al. Use of SOFA score to assess the incidence of organ dysfunction/failure in intensive care units: results of a multicenter, prospective study. Workung group on "sepsis-related problems" of the European Society of Intensive Care Medicine. Crit Care Med. 1998;26(11):1793-800.

12. Jones A, Trzeciak S, Kline J. The Sequential Organ Failure Assessment score for predicting outcome in patients with severe sepsis and evidence of hypoperfusion at the time of emergency department presentation. Crit Care Med. 2009;37(5):1649-54

13. Mikulicz J. WeitereErfahrungenuber die operative Behanlung der Perforations peritonitis. Arch KlinChir (Berl). 1889;39:756-84

14. Krukowski ZH, Matheson NA. Emergency surgery for diverticular disease complicated by generalized and faecal peritonitis: a review. Br J Surg. 1984; 71:921-7. doi:10.1002/bjs.1800711202.

15. Vermeulen J, Lange JF. Treatment of Perforated Diverticulitis with Generalized Peritonitis: Past, Present, and Future. World J Surg. 2010;34(3): 587-93. doi:10.1007/s00268-009-0372-0.

16. Level of evidence proposed from Centre for Evidence-Based Medicine of Oxford. http://www.essentialevidenceplus.com/product/ebmloe.cfm?show= oxford.

17. Liberati A, Altman DG, Tetzlaff J, Mulrow C, Gøtzsche PC, loannidis JP, Clarke M, Devereaux PJ, Kleijnen J, Moher D. The PRISMA statement for reporting systematic reviews and meta-analyses of studies that evaluate health care interventions: explanation and elaboration. Ann Intern Med. 2009;151(4):W65-94.
18. Moher D, Liberati A, Tetzlaff J, Altman DG. Preferred reporting items for systematic reviews and meta-analyses: the PRISMA statement. Ann Int Med. 2009;151:264-9. doi:10.7326/0003-4819-151-4-200908180-00135.

19. Lockhart-Mummery P. Disease of the colon and their surgical treatment. Bristol: John Wright and Sons LTD; 1910. p. 181-2.

20. Judd ES, Pollock LW. Diverticulitis of colon. Ann Surg. 1924;80(3):425-38. doi: 10.1097/00000658-192409000-00014.

21. Rankin FW, Brown PW. Diverticulitis of the colon. SurgGynecol\&Obstet. 1930; 30:836-47.

22. Wheeler WI. Perforative diverticulitis of the colon: some problems during the treatment of a fatal case. Br Med J. 1930;4(1):5-6. doi:10.1136/bmj.1.3600.5.

23. Lockhart-Mummery JP. Diseases of the Rectum and colon and their surgical treatment. 2nd ed. London: Baillière, Tindall\&Cox; 1934

24. Eggers C. Diverticulitis and sigmoiditis. Ann Surg. 1931;94(4):648-69. doi:10.1097/00000658-193110000-00020.

25. Conway FM, Hitzrot JM. Diverticulitis of the colon: a report of 36 cases from the New York Hospital. Ann Surg. 1931;94(4):614-39.

26. Hunt VC. Diverticulosis and diverticulitis of the colon. Cal West Med. 1934; 40(2):98-102.

27. Smithwick RH. Experiences with the surgical management of diverticulitis of the sigmoid. Ann Surg. 1942;115(6):969-85. doi:10.1097/00000658-194206000-00010.

28. Pemberton JD, Black BM, Maino CR. Progress in the surgical management of diverticulitis of the sigmoid colon. SurgGynecolObstet. 1947;85(4):523-34.

29. Boyden AM. The surgical treatment of diverticulitis of the colon. Ann Surg. 1950;132(1):94-109.

30. Eggers C. Acute diverticulitis and sigmoiditis. Ann Surg. 1941;113(1):15-29. doi:10.1097/00000658-194101000-00003.

31. Arnheim EE. Diverticulitis of the colon with special reference to the surgical complications. Ann Surg. 1940;112(3):352-69. doi:10.1097/00000658194009000-00004.

32. Gregg RO. The place of emergency resection in the management of obstructing and perforating lesions of the colon. Surgery. 1955:37(5):754-61.

33. Ryan P. Emergency resection and anastomosis for perforated sigmoid diverticulitis. Br J Surg. 1958:45(194):611-6. doi:10.1002/bjs.18004519409.

34. Belding $\mathrm{HH}$. Acute perforated diverticulitis of the sigmoid colon with generalized peritonitis. AMA Arch Surg. 1957;74(4):511-5. doi:10.1001/archsurg. 1957.01280100029004.

35. MacLaren IF. Perforated diverticulitis: a survey of 75 cases. J R CollSurgEdinb. 1957;3(2):129-44.

36. Hughes ES, Shaw HM. Acute diverticulitis of the colon with peritonitis. Med J Aust. 1952;1(8):259-60.

37. Lloyd-Davies OV. Diverticulitis. Proc R Soc Med. 1953;46(6):407-16.

38. Welch CE, Allen AW, Donaldson GA. An appraisal of resection of the colon for diverticulitis of the sigmoid. Ann Surg. 1953;138(3):332-43. doi:10.1097/ 00000658-195313830-00005.

39. Lewis JE, Hurwitz A. Surgical treatment of sigmoid diverticulitis. Surgery. 1953:33(4):481-94

40. Edwards HC. Intestinal diverticulosis and diverticulitis. Ann R CollSurgEngl. 1954;14(6):371-88.

41. Scarborough RA. Diverticulitis of the colon; surgical treatment. Calif Med. 1954;80(6):445-8.

42. Welch CE. The problem of diverticulitis; surgical management. Calif Med. 1955:83(6):405-9.

43. Ransom HK. Treatment of diverticulitis of the colon: Choice of operation. Am J Surg. 1956:92(5):672-7.

44. Bacon HE, Valiente MA. Surgical management of diverticulitis. Am J Surg. 1956;91(2):178-83. doi:10.1016/S0002-9610(56)80137-2.

45. McGregor RA, Bacon HE. Diverticular disease of the colon. Dis Colon Rectum. 1958;1(3):197-204. doi:10.1007/BF02616832.

46. O'Brien SE, Mustard Kl. Surgical management of diverticulitis of the sigmoid colon. Can Med Assoc J. 1959:80(4):257-61.

47. Brown DB, Toomey WF. Diverticular disease of the colon. A review of 258 cases. Br J Surg. 1960;47(205):485-93. doi:10.1002/bjs.18004720506.

48. Greig GW. The Surgical treatment of diverticulitis of the colon. A review of 38 cases. Ulster Med J. 1960;29(2):127-32.

49. Staunton MD. Treatment of Perforated Diverticulitis Coli. Br Med J. 1962; 1(5282):916-8. doi:10.1136/bmj.1.5282.916

50. Smiley DF. Perforated sigmoid diverticulitis with spreading peritonitis. Am J Surg. 1966;111(3):431-4. doi:10.1016/S0002-9610(66)80022-3.

51. Boyden AM. Two-stage Resection of the Sigmoid. Ann Surg. 1961;154 Suppl $6: 210-4$. 
52. Donald DC. Current Trends in the surgical treatment of diverticulitis of the colon: Review of Thirty-Seven Cases. Ann Surg. 1961;153(3):373-7. doi:10. 1097/00000658-196103000-00006.

53. Beard RG, Gazet JC. Perforated diverticulitis (of the colon) with generalized peritonitis. Guys Hosp Rep. 1961;110:263-72.

54. Estrada RL, Hoehn RJ, Robertson HR. Diverticulitis of the distal colon; twenty-five years' experience. Postgrad Med. 1962;31:30-6.

55. Hughes ES, Cuthbertson AM, Carden AB. The surgical management of acute diverticulitis. Med J Aust. 1963;50(1):780-2.

56. Linder JM, Hoffman S. Exteriorization in the surgical management of acute free perforations in diverticulitis of the sigmoid colon. SurgGynecolObstet. 1962;114:755-7.

57. Hartley RC. Dangerson of diverticulis Coli. An estimation of the place of resection in avoidance of complications. Br J Surg. 1964;51:45-9.

58. Large JM. Tretment of perforated diverticulitis. Lancet. 1964;22(1):413-4

59. Madden JL. Primary resection and anastomosis in the treatment of perforated lesions of the colon. Am Surg. 1965;31(12):781-6.

60. Cochrane HL. Diverticula of colon. Postgrad Med J. 1965;41(481):697-8. doi:10.1136/pgmj.41.481.697.

61. Dawson JL, Hanon I, Roxburgh RA. Diverticulitis coli Complicated by diffuse peritonitis. Br J Surg. 1965;52:354-7. doi:10.1002/bjs.1800520509.

62. Bacon HE, Pezzutti JE. Adequate Resection for diverticulitis of the colon. Arch Surg. 1966;92(1):58-9. doi:10.1001/arcsurg.1966.01320190060013.

63. Bolt DE, Hughes LE. Diverticulitis: a follow up of 100 cases. Br Med J. 1966;1: 1205-9. doi:10.1136/bmj.1.5497.1205.

64. Byrne RV. Primary resection of the colon for perforated diverticulum. Am J Surg. 1966;112(2):273-8. doi:10.1016/0002-9610(66)90019-5.

65. Watkins GL, Oliver GA. Management of perforative sigmoid diverticulitis with diffusing peritonitis. Arch Surg. 1966;92(6):928-33. doi:10.10001/ archsurg.1966.01320240116024

66. Moseley RV, Ross FP. Sigmoid diverticulitis: evaluation of current practice in a community hospital. Ann Surg. 1966;164(2):275-83. doi:10.1097/00000658196608000-00014.

67. Giffin JM, Butcher HR, Ackerman LV. Surgical management of colonic diverticulitis. Arch Surg. 1967;94(5):619-26. doi:10.1001/archsurg.1967.01330110035005.

68. Levy SB, Fitts WT, Lench JB. Surgical treatment of diverticular disease of the colon: evaluation of an eleven-year period. Ann Surg. 1967;166(6):947-54. doi:10.1097/00000658-196712000-00010.

69. Localio SA, Stahl WM. Diverticular disease of the alimentary tract. I The colon CurrProbl Surg. 1967;4(12):1-78. doi:10.1016/S0011-3840(67)80010-8.

70. Colcock BP. Surgical treatment of diverticulitis. Twenty years' experience. Am J Surg. 1968;115(2):264-70. doi:10.1016/0002-9610(68)90037-8.

71. Roxburgh RA, Dawson $J$, Yeo R. Emergency resection in treatment of diverticular disease complicated by peritonitis. Br Med J. 1968;5616:465-6. doi:10.1136/bmj.3.5616.465.

72. Rodkey GV, Welch CE. Surgical management of colonic diverticulitis with free perforation or abscess formation. Am J Surg. 1969;117(2):265-9. doi:10.1016/0002-9610(69)90313-4.

73. Moore HD. Emergency treatment of diverticulitis of the Sigmoid Flexure. Disease of the colon Rectum. 1969;12(1):22-5. doi:10.1007/BF02617191.

74. Dandekar NV, McCann WJ. Primary resection and anastomosis in the management of perforation of diverticulitis of the sigmoid flexure and diffuse peritonitis. Dis Colon Rectum. 1969;12(3):172-5. doi:10.1007/BF02617805.

75. Fenger C, Nyholm K, Amdrup E. Diverticulitis of the colon. Acta ChirScand Suppl. 1969;396:114-20.

76. Reiss R. Free perforation in sigmoid diverticulitis: two-stage therapy. Dis Colon Rectum. 1969;12(6):453-6. doi:10.1007/BF02617733.

77. Tagart RE. Diverticular disease of the colon. Clinical aspects. Br J Surg. 1969; 56(6):417-23. doi:10.1002/bjs.1800560605.

78. Botsford TW, Zollinger RM. Diverticulitis of the colon. SurgGynecolObstet. 1969;128(6):1209-14.

79. Mitty WF, Befeler D, Grossi C, Rousselot LM. Surgical management of complications of diverticulitis in patients over seventy years of age. Am J Surg. 1969;117(2):270-7. doi:10.1016/0002-9610(69)90314-6.

80. Killingkack MJ. Acute diverticulitis: progress report, Australasian survey (1967-1969). Dis Colon Rectum. 1970;13(6):444-7. PMID:5501400.

81. Garnjobst W, Hardwick C. Further criteria for anastomosis in diverticulitis of the sigmoid colon. American J of Surg. 1970;120(2):264-9. doi:10.1016/ S0002-9610(70)80122-2.

82. Relly MC. Colonic diverticula. Surgical management. Br Med J. 1970;3(5722): 570-3. doi:10.1136/bmj.3.5722.570.
83. Ponka JL. Emergency surgical operations for diverticular diseases. Dis Colon Rectum. 1970;13(3):235-42. doi:10.1007/BF02617215.

84. Barabas AP. Peritonitis due to diverticular disease of the colon: reiew of 44 cases. Proc R Soc Med. 1971;64(3):253-4.

85. Botsford TW, Zollinger RM, Hicks R. Mortality of the surgical treatment of diverticulitis. Am J Surg. 1971;121(6):702-5. doi:10.1016/0002-9610(71)90050-X.

86. Byrne JJ, Garick El. Surgical treatment of diverticulitis. Am J Surg. 1971; 121(4):379-84. doi:10.1016/0002-9610(71)90226-1.

87. Miller DW, Wichern WA. Perforated sigmoid diverticulitis. Appraisal of primary versus delayed resection. Am J Surg. 1971;121(5):536-40.

88. Watkins $G L$, Oliver GA. Surgical treatment of acute perforative sigmoid diverticulitis. Surgery. 1971;69(2):215-9.

89. Whelan CS, Furcinitti JF, Lavarreda C. Surgical management of perforated lesions of the colon with diffusing peritonitis. Am J Surg. 1971;121(4):374-8. doi:10.1016/0002-9610(71)90225-X.

90. Endrey-Walder $P$, Judd ES. Acute perforating diverticulitis. Emergency surgical treatment. Minn Med. 1973;56(1):27-30.

91. Labow SB, Salvati EP, Rubin RJ. The Hartman procedure in the treatment of diverticular disease. Dis Colon Rectum. 1973;16(5):392-4.

92. Graves HA, Franklin RM, Robbins LB, Sawyers JL. Surgical management of perforated diverticulitis of the colon. Am Surg. 1973;39(3):142-7.

93. Laimon H. Hartmann resection for acute diverticulitis. Rev Surg. 1974;31(1):1-6.

94. Targart RE General. Peritonitis and haemorrhage complicating colonic diverticular disease. Ann R Surg Engl. 1974;55(4):175-83.

95. Rodkey GV, Welch CE. Colonic diverticular disease with surgical treatment. A study of 338 cases. SurgClin North Am. 1974;54(3):655-74.

96. Ryan P. Emergency resection and anastomosis for perforated sigmoid diverticulitis. Aust N Z J Surg. 1974;44(1):16-20. doi:10.1111/j.1445-2197.1974.tb06511.x.

97. Tolins SH. Surgical treatment of diverticulitis. Experience at a large Municipal Hospital. JAMA. 1975;232(8):830-2. doi:10.1001/jama.232.8.830.

98. Nilsson LO. Surgical treatment of perforations of the sigmoid colon. Acta ChirScand. 1976;142(6):467-9.

99. Berardi RS, Siroospour D. Diverticular disorders of the colon: results of treatment in 128 patients. IntSurg. 1976;61(9):490-3.

100. Saegesser M. ChirurgischeOperationslehre. Bern: Max Ort, Verlag, Jahr; 1975.

101. Classen JN, Bonardi R, O'Mara CS, Finney DC, Sterioff S. Surgical treatment of acute diverticulitis by staged procedures. Ann Surg. 1976;184(5):582-6. doi: 10.1097/00000658-197611000-00008.

102. Himal HS, Ashby DB, Duignan JP, Richardson DM, Miller JL, MacLean LD. Management of perforating diverticulitis of the colon. SurgGynecolObstet. 1977;144(2):225-6.

103. Eng K, Ranson JH, Localio SA. Resection of the perforated segment. A significant advance in treatment of diverticulitis with free perforation or abscess. Am J Surg. 1977;133(1):67-72.

104. Nahrwold DL, Demuth WE. Diverticulitis with perforation into the peritoneal cavity. Ann Surg. 1977;185(1):80-3. doi:10.1097/00000658197701000-00013.

105. Sweatman Jr CA, Aldrete JS. The surgical management of diverticular disease of the colon complicated by perforation. SurgGynecolObstet. 1977; 144(1):47-50.

106. Malafosse M, Gallot D, Loygue J. General peritonitis complicating diverticular sigmoiditis. Med Chir Dig. 1978;7(5):397-400.

107. Morgenstern L, Weiner R, Michel SL. 'Malignant' diverticulitis: a clinical entity. Arch Surg. 1979;114(10):1112-6. doi:10.1001/archsurg.1979.01370340018002.

108. Howe HJ, Casali RE, Westbrook KC, Thompson BW, Read RC. Acute perforations of the sigmoid colon secondary to diverticulitis. Am J Surg. 1979;137(2):184-7. doi:10.1016/0002-9610(79)90141-7.

109. Nunes GC, Robnett AH, Kremer RM, Ahlquist Jr RE. The Hartmann procedure for complications of diverticulitis. Arch Surg. 1979;114(4):425-9. doi:10.1001/ archsurg.1979.01370280079011.

110. Haglund U, Hellberg R, Johnsén C, Hultén L. Complicated diverticular disease of the sigmoid colon. An analysis of short and long term outcome in 392 patients. Ann ChirGynaecol. 1979;68(2):41-6.

111. Thow GB. Emergency left colon resection with primary anastomosis. Dis Colon Rectum. 1980;23(1):17-24. doi:10.1007/BF02587195.

112. Theile D. The management of perforated diverticulitis with diffuse peritonitis Aust N Z J Surg. 1980;50(1):47-9. doi:10.1111/j.1445-2197.1980.tb04490.x.

113. Greif JM, Fried G, McSherry CK. Surgical treatment of perforated diverticulitis of the sigmoid colon. Dis Colon Rectum. 1980;23(7):483-7. doi:10.1007/ BF02987083. 
114. Mikulicz J. ChirurgischeErfahrungen fiber das Darmcarcinom. Arch $\mathrm{f}$ klin Chir. 1903:69:28-47.

115. Mayo WJ, Wilson LB, Griffin HZ. Acquired diverticulitis of the large intestine. SurgGynec\&Obst. 1907:5:8-15.

116. Hartmann $\mathrm{H}$. Nouveau procédéd'ablation des cancers de la partieterminale du colon pelvien. CongresFrancais de Chirurgia. 1923;30:2241

117. Painter NS. Diverticular disease of the colon. London: Norgine LTD; 1977.

118. Arnheim EE. Diverticulitis of the colon with special reference to the surgical complication. Ann Surg. 1940;112(3):352-69. doi:10.1097/00000658194009000-00004.

119. Opelka F. In: Beck DE, editor. Diverticular disease. St Louis: QMP Inc; 1997. p. 217-33.

120. Crile Jr G. Dangers of conservative surgery in abdominal emergencies. Surgery. 1954;35(1):122-3.

121. Marshall JC. Principles of source control in the management of sepsis. Crit Care Clin. 2009;25(4):753-68.

122. Painter NS. Diverticular disease of the colon. London: Heinemann; 1975.

123. Parks TG. Natural history of diverticular disease of the colon. Clin Gastroenterology. 1975;4(1):53-69.

124. Maingot R. Abdominal operations. New York: Appleton; 1955.

125. Krukowski ZH, Matheson NA. Emergency surgery for diverticular disease complicated by generalized and fecal peritonitis: a review. Br J Surg. 1984; 71:921-7.

126. Kronborg O. Treatment of perforated sigmoid diverticulitis: a prospective randomized trial. Br J Surg. 1993;80:505-7. doi:10.1002/bjs.1800800434.

127. Zeitoin G, Laurent A, Rouffet F, Hay J, Fingerhut A, Paquet J, Peillon C, Research TF. Multicentre, randomized clinical trial of primary versus secondary sigmoid resection in generalized peritonitis complicating sigmoid diverticulitis. $\mathrm{Br} J$ Surg. 2000;87:1366-74. doi:10.1046/j.1365-2168.2000.01552.x.

128. Nagorney DM, Adson MA, Pemberton JH. Sigmoid diverticulitis with perforation and generalized peritonitis. Dis Colon Rectum. 1985;28(2):71-5. doi:10.1007/BF02552645

129. Finlay IG, Carter DC. A comparison of emergency resection and staged management in perforated diverticular disease. Dis Colon Rectum. 1987; 30(12):929-33. doi:10.1007/BF02554278.

130. Cirocchi R, Trastulli S, Desiderio J, Listorti C, Boselli C, Parisi A, Noya G, Liu L. Treatment of Hinchey stage III-IV diverticulitis: a systematic review and meta-analysis International. Int J Colorectal Dis. 2013;28(4):447-57. doi:10. 1007/S00384-012-1622-4.

131. Wong WD, Wexner SD, Lowry A, Vernava A, Burnstein M, Denstman F, Fazio V, Kerner B, Moore R, Oliver G, Peters W, Ross T, Senatore P, Simmang C. Practice parameters for the treatment of sigmoid diverticulitis-supporting documentation. The Standards Task Force. Dis Colon Rectum. 2000;43(3): 290-7. doi:10.1007/BF02258291.

132. Salem L, Flum DR. Primary anastomosis or Hartmann's procedure for patients with diverticular peritonitis? A systematic review. Dis Colon Rectum. 2004:47(11):1953-64. doi:10.1007/s10350-004-0701-1.

133. Constantinides VA, Tekkis PP, Athanasiou T, Aziz O, Purkayastha S, Remzi FH, Fazio WW, Aydin N, Darzi A, Senapati A. Primary resection with anastomosis vs. Hartmann's procedure in nonelective surgery for acute colonic diverticulitis: a systematic review. Dis Colon Rectum. 2006;49(7):966-81. doi: 10.1007/s10350-006-0547-9

134. Abbas S. Resection and primary anastomosis in acute complicated diverticulitis, a systematic review of the literature. Int J Colorectal Dis. 2007;22(4):351-7. doi:10.1007/s00384-005-0059-4.

135. Lorusso D, Gilberti A, et al. Non-Elective Surgery for Acute Complicated Diverticulitis. Primary Resection-Anastomosis or Hartmann's Procedure? A Systematic Review and Meta-Analysis. Journal of Surgery. 2016;12(2):43-9. doi:10.7438/1584-9341-12-2-1.

136. Raffety J, Shellito P, Hyman NH, Buie WD. Practice parameters for sigmoid diverticulitis. Dis Colon Rectum. 2006:49(7):939-44.

137. Binda GA, Karas JR, Serventi A, Sokmen S, Amato A, Hydo L, Bergamaschi R. Primary anastomosis vs nonrestorative resection for perforated diverticulitis with peritonitis: a prematurely terminated randomized controlled trial. ColorectalDis. 2012;14(11):1403-10. doi:10.1111/j.1463-1318.2012.03117.x.

138. Oberkofler CE, Rickenbacher A, Raptis DA, Lehmann K, Villiger P, Buchl C, Grieder F, Gelpke H, Decurtins M, Tempia-Caliera AA, DemartinesN $H D$, Clavien PA, Breitenstein S. A multicenter randomized clinical trial of primary anastomosis or Hartmann's procedure for perforated leftcolonic diverticulitis with purulent or fecal peritonitis. Ann Surg. 2012;256(5): 819-26. doi:10.1097/SLA.0b013e31827324ba. discussion 826-7.
139. Panis Y. A multicenter randomized clinical trial of primary anastomosis or Hartmann's procedure for perforated left colonic diverticulitis with purulent or fecal peritonitis. Ann Surg. 2012;256:826.

140. Hold M, Denck H, Bull P. Surgical management of perforating diverticular disease in Austria. Int J Colorectal Dis. 1990;5(4):195-9. doi:10.1007/BF00303274.

141. Gooszen AW, Gooszen HG, Veerman W, Van Dongen VM, Hermans J, KlienKranenbarg E, Tollenaar RA. Operative treatment of acute complications of diverticular disease: primary or secondary anastomosis after sigmoid resection. Eur J Surg. 2001;167(1):35-9.

142. Schilling MK, Maurer CA, Kollmar O, Büchler MW. Primary vs. secondary anastomosis after sigmoid colon resection for perforated diverticulitis (Hinchey Stage III and IV): a prospective outcome and cost analysis. Dis Colon Rectum. 2001:44(5):699-703. doi:10.1007/BF02234569. discussion 703-5.

143. Regenet N, Pessaux P, Hennekinne S, Lermite E, Tuech JJ, Brehant O, Arnaud JP. Primary anastomosis after intraoperative colonic lavage vs. Hartmann's procedure in generalized peritonitis complicating diverticular disease of the colon. Int J Colorectal Dis. 2003;18(6):503-7. doi:10.1007/s00384-003-0512-1.

144. Richter S, Lindemann W, Kollmar O, Pistorius GA, Maurer CA, Schilling MK One-stage sigmoid colon resection for perforated sigmoid diverticulitis (Hinchey stages III and IV). World J Surg. 2006;30(6):1027-32. doi:10.1007/ s00268-005-0439-5.

145. Trenti L, Biondo S, Golda T, Monica M, Kreisler E, Fraccalvieri D, Frago R, Jaurrieta E. Generalized peritonitis due to perforated diverticulitis: Hartmann's procedure or primary anastomosis? Int J Colorectal Dis. 2011; 26(3):377-84. doi:10.1007/s00384-010-1071-x.

146. Alanis A, Papanicolaou GK, Tadros RR, Fielding LP. Primary resection and anastomosis for treatment of acute diverticulitis. Dis Colon Rectum. 1989; 32(11):933-9.

147. Alizai PH, Schulze-Hagen M, Klink CD, Ulmer F, Roeth AA, et al. Primary anastomosis with a defunctioning stoma versus Hartmann's procedure for perforated diverticulitis-a comparison of stoma reversal rates. Int J Colorectal Dis. 2013;28:1681-8.

148. Blair NP, Germann E. Surgical management of acute sigmoid diverticulitis. Am J Surg. 2002;183:525-8.

149. Berry AR, Turner WH, Mortensen NJ, Kettlewell MG. Emergency surgery for complicated diverticular disease. A 5-year experience. Dis Colon Rectum. 1989:32:849-54.

150. Gawlick U, Nirula R. Resection and primary anastomosis with proximal diversion instead of Hartmann's: evolving the management of diverticulitis using NSQIP data. J Trauma Acute Care. 2012;72:807-14.

151. Herzog T, Janot M, Belyaev O, Sülberg D, Chromik AM, et al. Complicated sigmoid diverticulitis-Hartmann's procedure or primary anastomosis? Acta Chir Belg. 2011;111:378-83.

152. Kourtesis GJ, Williams RA, Wilson SE. Surgical options in acute diverticulitis: value of sigmoid resection in dealing with the septic focus. Aust N Z J Surg. 1988:58:955-9.

153. Mäkelä JT, Kiviniemi H, Laitinen S. Prognostic factors of perforated sigmoid diverticulitis in the elderly. Digest Surg. 2005;22:100-6.

154. Mueller MH, Karpitschka M, Renz B, Kleespies A, Kasparek MS, et al. Comorbidity and postsurgical outcome in patients with perforated sigmoid diverticulitis. Int J Colorectal Dis. 2011;26:227-34.

155. Pasternak I, Dietrich M, Woodman R, Metzger U, Wattchow DA, et al. Use of severity classification systems in the surgical decision-making process in emergency laparotomy for perforated diverticulitis. Int J Colorectal Dis. 2010;25:463-70.

156. Saccomani GE, Santi F, Gramegna A. Primary resection with and without anastomosis for perforation of acute diverticulitis. Acta Chir Belg. 1993;93:169-72.

157. Smirniotis V, Tsoutsos D, Fotopoulos A, Pissiotis AC. Perforated diverticulitis: a surgical dilemma. Int Surg. 1992;77:44-7.

158. Stumpf MJ, Vinces FY, Edwards J. Is primary anastomosis safe in the surgical management of complications of acute diverticulitis? Am Surg. 2007;73: 787790.

159. Tabbara M, Velmahos GC, Butt MU, Chang Y, Spaniolas K, et al. Missed opportunities for primary repair in complicated acute diverticulitis. Surgery. 2010;148:919-24.

160. Zingg U, Pasternak I, Dietrich M, Seifert B, Oertli D, et al. Primary anastomosis vs Hartmann's procedure in patients undergoing emergency left colectomy for perforated diverticulitis. Colorectal Dis. 2010;12:54-60.

161. Tudor RG, Farmakis N, Keighley M. National audit of complicated diverticular disease: analysis of index cases. Br J Surg. 1994;81:730-2. 
162. Vermeulen J, Akkersdijk GP, Gosselink MP, Hop WC, Mannaerts GH, et al. Outcome after emergency surgery for acute perforated diverticulitis in 200 cases. Digest Surg. 2007;24:361-6.

163. O'Sullivan GC, Murphy D, O'Brien MG, Ireland A. Laparoscopic management of generalized peritonitis due to perforated colonic diverticula. Am J Surg. 1996;171:432-34

164. Myers E, Hurley M, O'Sullivan GC, Kavanagh D, Wilson I, Winter DC. Laparoscopic peritoneal lavage for generalized peritonitis due to perforated diverticulitis. Br J Surg. 2008;95:97-101.

165. Toorenvliet BR, Swank H, Schoones JW, Hamming JF, Bemelman WA. Laparoscopic peritoneal lavage for perforated colonic diverticulitis: a systematic review. Colorectal Dis. 2010;12(9):862-7. doi:10.1111/j.1463-1318.2009.02052.x.

166. Vennix S, Musters GD, Mulder IM, Swank HA, Consten EC, Belgers EH, Van Gelovan AA, Gerhards MF, Goveart MJ, Van Grevenstein WM, Hoofwijk AG, Kruyt PM, Nienhuijs SW, Boemeester MA, Vermeulen J, Van Dieren S, Lange JF, Bemelman WA. Ladies trial collaborators. Laparoscopic peritoneal lavage or sigmoidectomy for perforated diverticulitis with purulent peritonitis: a multicentre, parallel-group, randomised, open-label trial. Lancet. 2015;386: 1269-77. doi:10.1016/S0140-6736(15)61168-0.

167. Angenete $E$, Thornell A, Burcharth J, Pommergaard HC, Skullman S, Bisgaard T, Jess P, Lackberg Z, Matthiessen P, Heath J, Roesenberg J, Haglind E. Laparoscopic lavage is feasible and safe for the treatment of perforated diverticulitis with purulent peritonitis: the first results from the randomized controlled trial DILALA. Ann Surg. 2016;263:117-22. doi:10.1097/SLA.0000000000001061.

168. Schultz JK, Yaqub S, Wallon C, Blecic L, Forsmo HM, Folkesson J, Buchwald P, Körner H, Dahl FA, Oresland T, SCANDIV Study Group. G. Laparoscopic lavage vs primary resection for Acute perforated diverticulitis: The SCANDIV Randomized Clinica Trial. JAMA. 2015;314(13):1364-75. doi:10.1001/jama. 2015.12076.

169. Mandrioli M, Tugnoli G, Di Saverio S. Laparoscopic lavage vs Primary Resection for Perforated Diverticulitis. JAMA. 2016;315(10):1053. doi:10.1001/ jama.2015.17864

170. Slim K. Role of peritoneal lavage for sigmoid perforation peritonitis surgery: What do the meta-analyses tell us? Journal of Visceral Surgery (2016). (in press)

171. Ceresoli M, Coccolini F, Montori G, Catena F, Sartelli M, Ansaloni L. Laparoscopic lavage versus resection in perforated diverticulitis with purulent peritonitis: a meta-analysis of randomized controlled trials. World J Emerg Surg. 2016;30(1):42.

172. Angenete E, Bock D, Rosenberg J, Haglind E. Laparoscopic lavage is superior to colon resection for perforated purulent diverticulitis-a meta-analysis. Int J Colorectal Dis. 2016. (in press)

173. Marshall JR, Buchwald PL, Gandhi J, Schultz JK, Hider PN, Frizelle FA, et al. Laparoscopic Lavage in the Management of Hinchey Grade III Diverticulitis: A Systematic Review. Ann Surg. 2016.

174. Cirocchi R, Weber DG, Di Saverio S, et al. Laparoscopic lavage versus surgical resection for acute diverticulitis with generalised peritonitis: a systematic review and meta-analysis. Techniques in Coloproctology. 2016; 21:93-110

175. Karulf RE. Diverticular disease. Clin Colon Rectal Surg. 2004;17(3):145. doi:10. 1055/s-2004-832694.

176. Andreozzi P, Zito FP, Sarnelli G, et al. Management of diverticulitis and prevention of recurrence. EMJ Gastroenterol. 2015;4(1):95-100.

177. Binda GA, Prandi M. Storia naturale della diverticolite del colon. UCP News. 1999;3(S1):14-6.

178. Everhart JE, Ruhl CE. Burden of digestive diseases in the United States Part III: Liver, biliary tract, and pancreas. Gastroenterology. 2009;136(4):1134-44. doi:10.1053/j.gastro.2009.02.038

179. Khalil H, Yoo J. Colorectal Emergencies: perforated diverticulitis (operative and nonoperative management. J GastrointestSurg. 2014;18(4):865-8. doi:10.1007/s11605-013-2352-9.

180. Papagrigoriadis S, Debrah S, Koreli A, Husain A. A Impact of diverticular disease on hospital costs and activity. Colorectal Dis. 2004;6(2):81-4. doi:10.1111/j.1463-1318.2004.00532.x.

181. Etzioni DA, Mack TM, Beart RW, Kaiser AM. Diverticulitis in the United States: 1998-2005: changing patterns of disease and treatment. Ann Surg. 2009; 249(2):210-7. doi:10.1097/SLA.0b013e3181952888.

182. Solomkin JS, Mazuski JE, Bradley JS, Rodvold KA, Goldstein EJ, Baron EJ, et al. Diagnosis and management of complicated intra-abdominal infection in adults and children: guidelines by the Surgical Infection Society and the Infectious Diseases Society of America. Surg Infect (Larchmt). 2010;11:79-109.
183. Mazuski JE, Sawyer RG, Nathens AB, DiPiro JT, Schein M, Kudsk KA, et al. The Surgical Infection Society guidelines on antimicrobial therapy for intraabdominal infections: an executive summary. Surg Infect (Larchmt). 2002:3:161-73.

184. Sartelli M, Viale P, Catena F, Ansaloni L, Moore E, Malangoni M, et al. WSES guidelines for management of intra-abdominal infections. World J Emerg Surg. 2013;8:3.

185. Chow AW, Evans GA, Nathens AB, Ball CG, Hansen G, Harding GK, et al. Canadian practice guidelines for surgical intra-abdominal infections. Can J Infect Dis Med Microbiol. 2010;21:11-37.

186. Montravers P, Dupont $H$, Leone M, Constantin JM, Mertes PM, Société française d'anesthésie et de réanimation (Sfar), et al. Guidelines for management of intra-abdominal infections. Anaesth Crit Care Pain Med. 2015;34:117-30.

187. Sartelli M, Weber DG, Ruppé E, Bassetti M, Wright BJ, Ansaloni L, et al. Antimicrobials: a global alliance for optimizing their rational use in intraabdominal infections (AGORA). World J Emerg Surg. 2016;15:11-33.

188. Berne J, Velmahos G, Chan L, Asensio JA, Demetriades D. The high morbidity of colostomy closure after trauma: further support for the primary repair of colon injuries. Surgery. 1998;123:157-64. doi:10.1016/ S0039-6060(98)70253-3.

189. Antolovic D, Reissfelder C, Özkan T, Galindo L, Büchler MW, Koch M, Weitz J. Restoration of intestinal continuity after Hartmann's procedure- not a benign operation. Are there predictors for morbidity? Langenbeck's Arch Surg. 2011;396(7):989-96. doi:10.1007/s00423-011-0763-1.

190. Roque-Castellano C, Marchena-Gomez J, Hemmersbach-Miller M, AcostaMerida A, Rodriguez-Mendez A, Fariña-Castro R, Hernandez-Romero J. Analysis of the factors related to the decision of restoring intestinal continuity after Hartmann's procedure. Int J Colorectal Dis. 2007;22(9):1091-6. doi:10.1007/s00384-007-0272-4.

191. Keck JO, Collopy BT, Ryan PJ, Fink R, Mackay JR, Woods RJ. Reversal of Hartmann's procedure: effect of timing and technique on ease and safety. Dis Colon Rectum. 1994;37(3):243-8.

192. Cirocchi R, Trastulli S, Vettoretto N, Milani D, Cavaliere D, Renzi C, Adamenko O, Desiderio J, Burattini MF, Parisi A, Arezzo A, Fingerhut A. Laparoscopic peritoneal lavage: a definitive treatment for diverticular peritonitis or a "bridge" to elective laparoscopic sigmoidectomy? a systematic review. Medicine (Baltimore). 2015; 94(1):e334.

193. Afshar S, Kurer MA. Laparoscopic peritoneal lavage for perforated diverticulitis: are we any further forward? Colorectal Dis. 2016. doi:10.1111/codi.13404.

194. Leff El, Groff W, Rubin RJ, Eisenstat TE, Salvati EP. Use of ureteral catheters in colonic and rectal surgery. Dis Colon Rectum. 1982;25(5):457-60.

195. Sheikh FA, Khubchandani IT. Prophylactic ureteric catheters in colon surgery- How safe are they? Report of three cases. Dis Colon Rectum. 1990;33:508-10.

196. Kyzer S, Gordon PH. The prophylactic use of ureteral catheters during colorectal operations. Am Surg. 1994;60:212-9.

197. Bothwell WN, Bleicher RJ, Dent TL. Prophylactic ureteral catheterization in colon surgery. A 5-year review. Dis Colon Rectum. 1994;37:330-4.

198. Palaniappa NC, Telem DA, Ranasinghe NE, Divino CM. Incidence of iatrogenic ureteral injury after laparoscopic colectomy. Arch Surg. 2012;147:267-71.

199. Zafar SN, Ahaghotu CA, Libuit L, Ortega G, Coleman PW, et al. Ureteral injury after laparoscopic versus open colectomy. JSLS. 2014;18:3.

200. Chahin F, Dwivedi AJ, Paramesh A, Chau W, Agrawal S, et al. The implications of lighted ureteral stenting in laparoscopic colectomy. JSLS 2002;6:49-52.

201. Abcarian H, Pearl RK. A safe technique for resection of perforated sigmoid diverticulitis. Dis Colon Rectum. 1990;33:905-6.

202. Schein M, Paladugn R. Diverticulitis. In: Holzheimer RG, Mannick JA (Eds). Surgical Treatment: Evidence-Based and Problem-Oriented. Munich: Zuckschwerdt; 2001. https://www.ncbi.nlm.nih.gov/books/NBK6986/. Accessed 14 Dec 2016.

203. Brandt D, Gervaz P, Durmishi Y, Platon A, Morel P, Poletti PA. Percutaneous CTscan-guided drainage vs. antibiotherapy alone for Hinchey II diverticulitis: acase-control study. Dis Colon Rectum. 2006:49:1533-8.

204. Kumar RR, Kim JT, Haukoos JS, Macias LH, Dixon MR, Stamos MJ, Konyalian VR. Factors affecting the successful management of intra-abdominal abscesses with antibiotics and the need for percutaneous drainage. Dis Colon Rectum. 2006:49:183-9.

205. Siewert B, Tye G, Kruskal J, Sosna J, Opelka F, Raptopoulos V, et al. Impact of CT-guided drainage in the treatment of diverticular abscesses: size matters. AJR Am J Roentgenol. 2006;186:680-6. 
206. Lamb MN, Kaiser AM. Elective resection versus observation after nonoperative management of complicated diverticulitis with abscess: a systematic review and meta-analysis. Dis Colon Rectum. 2014;57:1430-40.

207. LapLAND laparoscopic lavage for acute nonfaeculent diverticulitis. 2009. Available at: https://clinicaltrials.gov/ct2/show/NCT01019239. Accessed 28 Dec 2006

208. Laparoscopic-lavage Observational Study (LLOS). Available at: https:// clinicaltrials.gov/ct2/show/NCT02662088?term=NCT02662088\&rank=1. Accessed 28 Dec 2006

209. Vennix S, Lips DJ, Di Saverio S, van Wagensveld BA, Brokelman WJ, Gerhards MF, van Geloven AA, van Dieren S, Lange JF, Bemelman WA. Acute laparoscopic and open sigmoidectomy for perforated diverticulitis: a propensity score-matched cohort. Surg Endosc. 2016;30(9):3889-96. doi:10.1007/s00464-015-4694-8.

210. Di Saverio S, Vennix S, Birindelli A, Weber D, Lombardi R, Mandrioli M, Tarasconi A, Bemelman WA. Pushing the envelope: laparoscopy and primary anastomosis are technically feasible in stable patients with Hinchey IV perforated acute diverticulitis and gross faeculent peritonitis. Surg Endosc. 2016;30(12):5656-64

Submit your next manuscript to BioMed Central and we will help you at every step:

- We accept pre-submission inquiries

- Our selector tool helps you to find the most relevant journal

- We provide round the clock customer support

- Convenient online submission

- Thorough peer review

- Inclusion in PubMed and all major indexing services

- Maximum visibility for your research

Submit your manuscript at www.biomedcentral.com/submit
Biomed Central 